\title{
ARQUEOLOGÍA PÚBLICA, O EL USO SOCIAL DEL PATRIMONIO...'
}

\author{
Desiderio Vaquerizo Gil²
}

\begin{abstract}
"Todo lo que no se transmite a conciencia se pierde en el paso de una generación a otra. Lo que existió durante siglos desaparece en el curso de unos pocos años. Todo cambia muy rápido y muy poco tiempo después ya nadie recuerda cómo eran antes las cosas, y por lo tanto cree que han sido siempre así y que por sí solas se mantendrán invariables. Lo que ha sido parte de la conciencia común deja de existir y se convierte en referencias crípticas que nadie descifra, en palabras de un idioma perdido. La mayor parte del patrimonio complicado e inmenso de lo que se da por sabido desaparece en una gran catarata silenciosa que no deja recuerdos, como la memoria de alguien que acaba de morir" (A. Muñoz Molina, Todo lo que era sólido, Ed. Seix Barral Biblioteca Breve, $10^{\mathrm{a}}$ ed., Barcelona 2014, p. 200).
\end{abstract}

\section{Resumen:}

La Arqueología vive tiempos difíciles. Tras haber conocido una auténtica edad de oro de la mano del boom inmobiliario, la crisis se ha llevado por delante el endeble edificio que de forma un tanto temeraria habíamos construido sobre arenas movedizas, y ahora, tras la debacle y el recuento de víctimas, es llegado el momento de la reflexión y la autocrítica, del análisis sosegado, la ponderación y la catarsis, por muy dura que ésta sea. Es preciso detectar con urgencia los errores para no volver a caer en ellos, corregir sesgos para evitar seguir a la deriva y rentabilizar recursos, aunar esfuerzos en pro de un mayor corporativismo que acabe con la separación tradicional y falazmente enconada entre Academia y Arqueología Comercial y reivindique la Arqueología como ciencia, pero también como profesión. En este marco, nuevas corrientes epistemológicas como la genéricamente denominada Arqueología Pública tratan de reparar viejas obviedades, reintegrando de paso a la sociedad la responsabilidad sobre el patrimonio arqueológico que nunca le debió ser cuestionada. Un intento loable,

1 Este trabajo se inscribe en el marco del Proyecto de Investigación Del registro estratigráfico a la sociedad del conocimiento: el patrimonio arqueológico urbano y rural como agente de desarrollo sostenible (ciudad y territorio), financiado por la Secretaría de Estado de Investigación, Desarrollo e Innovación del Ministerio de Economía y Competitividad, en el marco del Programa estatal de Investigación, Desarrollo e Innovación orientada a los retos de la sociedad, Convocatoria 2013, Modalidad 1: Proyectos de I+D+I (Ref.: HAR2013-43389-R), del que soy Investigador Principal. También, es importante señalar el apoyo institucional y económico para el correcto desarrollo de nuestras actividades por parte de la Fundación Española para la Ciencia y la Tecnología del Ministerio de Economía y Competitividad (Fecyt), que financia desde hace algunos años diversos proyectos en el marco de Arqueología somos todos (vid. infra). Al respecto, por ejemplo, Vaquerizo 2014 y 2015 , a-e.

2 Grupo de Investigación Sísifo (PAIDI HUM-236. Universidad de Córdoba

Revista Otarq - ISSN 2530-4933

Vol. 2 2017, pp. 251-284 
sin duda, que no obstante se mueve a veces en el filo de la navaja. Desde la Universidad de Córdoba el Grupo de Investigación Sísifo se anticipó de alguna manera con la puesta en marcha a principios de 2011 de su proyecto de cultura científica Arqueología somos todos, que, siempre con la investigación como punto de partida y retorno, defiende la educación como clave de futuro y funciona con base en el principio de la cultura emprendedora.

\title{
Palabras clave:
}

Arqueología Comercial, Academia, Arqueología Pública, Cultura emprendedora, Mecenazgo.

\begin{abstract}
:
Archaeology has fallen on hard times; after the golden age that marched hand in hand with the construction boom came the crisis to demolish the frail structure so rashly built on quick-sands. Today, once the victims have been counted after the disaster, the moment has come for reflection, self criticism, cold analysis, deliberation and catarsis, however hard this may be. It is vital to identify the mistakes made in order to avoid them in the future, to correct distortions so as to stop drifting and start making the most of resources, sharing efforts in a common push to banish traditional sectarianism and the falsely exagerated divorce between Academic and Commercial Archaeology. The time has come to vindícate Archaeology as both science and profession. Within this framework new areas, such as what is commonly known as Public Archaeology, attempt to repair outdated postures, handing back to the general public the responsibility for archaeological patrimony that should never have been questioned. However, this undoubtedly praiseworthy attempt very often balances on a knife edge. At the University of Cordoba the Sisifo Research Group was ahead of its times in 2011 when it launched Arqueología Somos Todos -Archaeology is Us- a cultural and scientific project using research as its point of departure and return, defending education as the key to the future and working according to the precepts of cultural enterprise.
\end{abstract}

\section{Key words:}

Commercial Archaeology, Academy, Public Archaeology, Cultural Enterprise, Sponsorship 


\section{Arqueología para tiempos de crisis}

Tradicionalmente, la comunidad científica ha tendido a despreciar la divulgación ${ }^{3}$ por considerar que resta un tiempo valioso e insustituible a la investigación, verdadero leit motiv de la arqueología como ciencia histórica; premisa cierta, sin duda, pero con matices y sólo hasta cierto punto. Para que el trabajo científico alcance pleno sentido debe siempre revertir a la sociedad, que necesita entenderlo para suscribirlo, ponerlo a su servicio y financiarlo; más, si cabe, en tiempos de contracción económica, cuando la cultura es lo primero que se sacrifica, por superflua y "prescindible" ${ }^{\text {. }}$. De paso, la difusión supone un yacimiento de empleo no sólo para los arqueólogos, sino también para otros colectivos relacionados con el patrimonio, el turismo, la cultura, la hostelería, el arte... Quizá por eso, en el caso concreto de Córdoba, empezaron pronto los reconocimientos y, tras las críticas, también las conversiones (algunas de ellas bastante farisaicas). El papel de la Universidad es el de abrir camino, servir de modelo. Hoy, no paran de surgir empresas que buscan retorno económico en la divulgación histórica; como consecuencia, cada vez es más frecuente ver a gente "disfrazada" de romana, que en un sentido maniqueo de la didáctica aplicada a la arqueología ${ }^{5}$, intenta educar (supongo), al tiempo que vivir. Un objetivo digno y loable en sí mismo, de tintes paradójicos, no obstante, si nos detenemos a meditar sobre el hecho de que ese sesgo hacia la difusión olvida con frecuencia la investigación; y para poder divulgar es preciso generar conocimiento de manera sostenida, formarse a diario. En caso contrario, el ciclo se cortocircuita y conduce al desastre.

La difusión es necesaria, sí, pero sólo si sirve para transferir a la sociedad los resultados de quienes investigan, en un crecimiento simbiótico que genere historia y dote a ciudades y pueblos de nuevos recursos patrimoniales. Para ello es imprescindible antes analizar, publicar, conservar, señalizar, programar, nutrirse;

3 También, a desprestigiarla, por entender la transferencia de conocimiento como arqueología "de tercera". Entronca tal actitud con la indefinición del perfil profesional de esta última, que a pesar de la puesta en marcha de titulaciones específicas sigue sin ser reconocida como tal por el Ministerio de Trabajo. De entrada, arqueólogo es aquél que hace arqueología, lo que implica un acercamiento al pasado a través de los restos materiales, pero el espectro de tareas es tan amplio que parece absurdo adoptar de entrada posturas elitistas y excluyentes. Habrá, pues, que reflexionar profundamente sobre ello en los próximos años, supuesta la importancia creciente que están cobrando otras formas de hacer arqueología.

4 Así lo han entendido las instituciones, que desde hace algunos años exigen en todas las convocatorias (incluidas las de $\mathrm{I}+\mathrm{D}+\mathrm{i}$ ) la incorporación de programas de transferencia de los resultados obtenidos, o han creado líneas específicas de trabajo al respecto. El problema es que, en una contradictio in terminis cuando menos llamativa, la investigación derivada de estos temas sigue siendo tildada de "poco científica", menospreciada por los evaluadores y negada por las agencias y los organismos de evaluación universitaria, con lo que ello supone habitualmente de "suicidio" académico para quienes la practican.

5 Sobre el tema, vid. Cardona 2015. 
justo todo aquello que hoy apenas hacemos, rozando a veces el puro mercantilismo. Convertir nuestros escasos monumentos en escenarios para teatros, conciertos, catas de salmorejo, mercados, juegos o escenografías de más que dudoso alcance en algún caso, cuando hay tanto patrimonio exangüe, es invertir los términos, empezar la casa por el tejado, transformar en carnaval y fiesta lo que deberían ser rigor y cultura. Hemos de corregir nuestra tendencia a trivializar, a dar por hecho que los ciudadanos no son capaces de entender mensajes más profundos que el puro disfraz. En caso contrario contribuiremos a incrementar el componente exacerbadamente hedonista que nos domina, la mediocridad imperante, ese epicureísmo extraño proclamado día a día desde todos los ámbitos imaginables, que antes o después acabará estallando cual globo de helio. "Sólo quien alterna los placeres con ocupaciones serias saca de ambas cosas el merecido disfrute... Una vida compuesta sólo de aquéllos es tan insípida como despreciable", le comentaba Lord Chesterfield a su hijo en una de sus cartas (la CXCII), allá por 1750.

A día de hoy, la investigación arqueológica sensu stricto en nuestras ciudades históricas (hablo siempre en términos genéricos) es poco menos que inexistente, o se mantiene en precario con dificultades enormes de financiación, basada en el voluntarismo y el sacrificio personales, casi sin excepción desde la Universidad. Así ocurre en Córdoba. Por eso, el objetivo último del proyecto de cultura científica Arqueología somos todos (en adelante AST; vid. infra), que pocos parecen haber entendido, es demostrar que la difusión arqueológica, al tiempo que cierra el ciclo del trabajo científico, puede también convertirse en vía de financiación para el estudio y la exégesis, retroalimentando el proceso; ojo, no ya sólo para quienes integran el proyecto, sino también para otras empresas del ramo. Por eso, el hecho de que las instituciones apoyen sin dudarlo actividades de divulgación con frecuencia fútiles e insustanciales, mientras no invierten un solo céntimo en investigación, nos ha llevado a dar un nuevo giro a $A S T$, tratando de convertirlo en un proyecto comunitario. Su sostenimiento dependerá así, en último término, de la ciudadanía, de su capacidad crítica y su sentido del compromiso, de su necesidad de educación y su predisposición para implicarse, de su convencimiento de que conocer y potenciar nuestro patrimonio son el mejor modo de valorarlo y respetarlo, además de perfilarse como vías efectivísimas de futuro ${ }^{6}$. Es la hora de la verdad, la hora del mecenazgo activo. Pero de todo eso hablaré más abajo...

\section{El Patrimonio, como bien social y factor de desarrollo sostenible}

El artículo 9 del Convenio Europeo para la protección del patrimonio arqueológico de La Valetta fija el compromiso explícito de todos los Estados firmantes (entre los cuales España) en dos aspectos de enorme interés: "i)

6 Vid. http://www.arqueologiasomostodos.com/amigos/amigos.html. 
emprender acciones educativas con el fin de suscitar y desarrollar en la opinión pública la conciencia del valor del patrimonio arqueológico para el conocimiento del pasado y de los peligros que amenazan a su patrimonio"; y "ii. promover el acceso del público a los elementos importantes del patrimonio arqueológico, especialmente a los emplazamientos, y fomentar la exposición al público de selecciones adecuadas de objetos arqueológicos".

Este mismo espíritu es recogido por la Ley de Patrimonio Histórico Español de 1985, que en su Preámbulo declara lo siguiente: "Todas las medidas de protección y fomento que la Ley establece sólo cobran sentido si, al final, conducen a que un número cada vez mayor de ciudadanos pueda contemplar y disfrutar las obras que son herencia de la capacidad colectiva de un pueblo. Porque en un Estado democrático estos bienes deben estar adecuadamente puestos al servicio de la colectividad en el convencimiento de que con su disfrute se facilita el acceso a la cultura y que ésta, en definitiva, es camino seguro hacia la libertad de los pueblos". Finalmente, la Ley de Patrimonio Histórico Andaluz de 26 de noviembre de 2007, en su artículo 1, especifica: "es objeto de la Ley establecer el régimen jurídico del Patrimonio Histórico de Andalucía con el fin de garantizar su tutela, protección, conservación, salvaguarda y difusión, promover su enriquecimiento y uso como bien social y factor de desarrollo sostenible y asegurar su transmisión a las generaciones futuras".

Queda fijado así, de forma explícita, vertical y absolutamente incontestable, el que es, o debería ser, objetivo último de la Arqueología: revertir el conocimiento generado a la sociedad (que incluye desde la comunidad científica a los niveles iniciales de enseñanza), en una acción consciente y activa de transferencia e implicación con el entorno que en estos últimos años se viene materializando de manera controvertida y algo desigual en una nueva forma de hacer, calificada genéricamente de "Pública" o "Comunitaria"7, loable por definición (Almansa 2011c, 104), pero objeto ya de algunos excesos y denostada por muchos, quizá porque se teme.

Además de concebir la Arqueología como "una disciplina de gestión integral del Patrimonio, asentada sobre una cadena técnico-operativa que, en sí misma, alberga un potencial informativo enormemente interesante... demandado por sectores cada vez más amplios de la sociedad" (Marín Suárez et alii 2013, 431), la Public Archaeology parte, precisamente, de implicar a la ciudadanía en el proceso científico, entendido éste desde la fase de registro propiamente dicho (prospección, excavación, documentación o simple estudio de materiales), hasta que las estructuras, los artefactos y los ecofactos obtenidos son interpretados,

7 La tradición más importante en este sentido la tiene el mundo anglosajón, donde en cualquiera de los casos la realidad es muy diferente a la española, tanto desde el punto de vista legal como de percepción e implicación de la ciudadanía, no siempre para bien. Al respecto, vid. por ejemplo como trabajos recientes Henson 2009, o Simpson 2009, con bibliografía anterior. 
conservados si procede, difundidos y también rentabilizados en sentido amplio ${ }^{8}$. Todo ello desde un punto de partida indiscutible: que nuestra materia une a su componente histórico otro patrimonial y, en consecuencia, dadas sus evidentes potencialidades de mercado, además de conocimiento y capacidad de formación incorpora a su esencia como ciencia un componente emocional y estético, un valor simbólico destacado, y la posibilidad nada desdeñable en los tiempos que corren de generar retorno económico, en una auténtica cadena de valor ${ }^{9}$ que ciudades como Córdoba no han sabido todavía explotar en su verdadera dimensión.

Esta manera de entender las tareas arqueológicas ha despertado ya las reticencias de muchos; ha llegado incluso a ser descalificada o tildada de pura -y duramercantilización (La Linde 2013, 20 ss); acumulado críticas feroces desde ciertos sectores de la Universidad, que obvian con ello, entre otras cosas, las directrices emanadas estos últimos años de los organismos nacionales responsables de la investigación. Si, por el contrario, podría llegar a representar una forma nueva de reconducir nuestra disciplina haciéndola ganar en versatilidad, de adaptarse a la coyuntura histórica tan particular que vivimos abriendo campos inéditos de trabajo que complementen a la arqueología tradicional de investigación (hasta ahora, sostenida con fondos públicos), de "democratizar" el patrimonio evitando que Administración y arqueólogos vivamos en una burbuja, apropiados en exclusiva de él (Almansa 2011c, 96), el tiempo se encargará de dilucidarlo. Por el momento, empieza al menos a revelarse como un yacimiento de empleo de primera magnitud que, con base en el concepto más patrimonial de la disciplina, trata -consigue- de mantener el interés ciudadano por el pasado, convirtiéndolo en factor de reactivación, con componentes añadidos de carácter identitario, territorial, lúdico, pedagógico y de futuro, admitido siempre el legado material como acervo potencial y oportunidad, no como rémora.

La literatura reciente sobre el tema es tan abundante y variada ${ }^{10}$ que renuncio, de entrada, a entrar en su exégesis detallada, ante el riesgo, más que evidente, de no aportar nada al debate, capitalizado en buena medida, en lo referido a España, por los focos, activísimos, de las Comunidades de Madrid y Galicia. Entre

8 "... revertir beneficios a la comunidad debe ser la base de todo proyecto científico, máxime si éste ha sido sufragado con dinero público" (Pulido 2008, 322).

9 "... estudiar, excavar, proteger, restaurar, investigar, publicar, difundir, gestionar..." (Andreu, García 2013, 277).

10 Vid., por ejemplo, al respecto, Merriman 2004; Holtorf 2007; Bonacchi 2009; Vannini 2011; Liverani 2011; Almansa 2011c (este autor edita en inglés, desde 2011, la publicación online $A P$. Online Journal in Public Archaeology, pionera en España; www.arqueologiapublica.es); Skeates, McDavid, Carman 2012; Ayán, González, Rodríguez 2012; Ayán, Gago 2012; La Linde 2013; Ayán 2014; los trabajos contenidos en Almansa 2013a, o las Actas del I Congreso Internacional sobre Socialización del Patrimonio, celebrado en Malpartida de Cáceres entre los días 18 a 21 de septiembre de 2013, todavía inéditas en el momento de entregar estas líneas. 
los numerosos proyectos activos a día de hoy destacan, por ejemplo: A Lanzada (Sanxenxo, Pontevedra; Ayán, González, Rodríguez 2012); Cueva Pintada (Gáldar, Gran Canaria; Rodríguez Santana, Correa 2013); Los Bañales (Uncastillo, Zaragoza; Andreu, García 2013); Torre dos Mouros (Lira-Carnota, A Coruña; Gago et alii 2013) ${ }^{11}$; Entorno Camila (Villanueva de los Infantes, Ciudad Real; MoyaJaleno 2013), o el consciente y militantemente poco objetivo"12 blog "Arqueología de la Guerra Civil", de la Universidad Complutense de Madrid (Marín Suárez et alii 2013).

Está claro que la sociedad tiene mucho que decir en la gestión del patrimonio y el conocimiento arqueológico, por lo que conviene, primero de todo, conocerla en detalle (Ruiz Zapatero 2012, 34) ${ }^{13}$. Sin embargo, eso que muchos han dado en Ilamar "democratización" de la arqueología no está en absoluto reñido con la Academia, por más que desde que aquélla tomó cuerpo como ciencia nos hayamos empeñado en trabajar al margen de la sociedad, en desarrollar una jerga propia no siempre inteligible, en enfocar los resultados de nuestras investigaciones sólo al cuerpo mismo de arqueólogos, en encapsularnos de forma temeraria. Aun así, hemos de ser conscientes como punto de partida de una verdad absoluta, y es que, como ya antes avanzaba, la difusión no tiene ningún sentido, ni se podría sostener por sí misma durante mucho tiempo, sin investigación que la retroalimente. Otra cosa son los egos desbordados y las actitudes despreciativas y excluyentes, que los hay y empiezan también a ser denunciados, no siempre con razón ni en los mejores términos (Ayán, González, Rodríguez 2012, 68; Albelda, Pardo, Real 2013, 320).

Del mismo modo, y dado que no existe aforismo sin su contrario, conviene reforzar los cuidados con el amateurismo, no confundir divulgación con participación directa en determinados procesos (por más que rigor y amenidad no sean en absoluto nociones contrapuestas), hacer de la educación un motor transformador que, al fin y a la postre, se nutre de datos accesibles sólo a especialistas. Así ocurre en otras ciencias, históricas o no, y nadie lo cuestiona. Habrá, por tanto, que poner atención especial a los extremos, porque de no manejar adecuadamente el discurso se incrementarán, reforzándolos, la cerrazón y el rechazo que por otra parte se critican, se agudizará sin remedio la fragmentación conceptual, incluso corporativa, que nos divide.

11 Este trabajo sirve además como síntesis historiográfica del desarrollo de la Arqueología Pública o Comunitaria en Galicia: "una Arqueología integradora que, partiendo de la interdisciplinariedad y el activismo cultural y político, haga verdaderamente partícipes del proceso de construcción del conocimiento sobre el pasado a los diferentes públicos, las comunidades locales y la comunidad virtual" (Gago et alii 2013, 293).

12 Referido mi adjetivo a la imparcialidad de partida que cabe exigir siempre, y sin concesiones, al historiador.

13 La "divulgación científica, a nivel básico, no quiere decir transmitir respuestas, sino preguntas", y en una estrategia entendida a largo plazo, además (Bruner 2012,37). 
Nada que matizar, por tanto, con relación a la filosofía "democratizadora", difusora y rentabilizadora de la arqueología así entendida aun a riesgo de acabar cayendo eventualmente en la arqueología extrema o la más pura mendicidad (Martínez Vallejo 2014, 159 ss.), por cuanto los sitios arqueológicos, y las ruinas más o menos monumentales que incorporan no se explican por sí mismos, sino que necesitan ser interpretados ${ }^{14}$. Tampoco, si se me apura, con respecto a la arqueología autogestionada (Vila et alii 2014) que, de alguna manera, aplicando una vuelta de tuerca a lo que hemos hecho siempre desde la Universidad, será clave en el futuro, dada la falta de apoyo económico por parte de las Administraciones, y el cada vez más determinante papel de la denominada cultura emprendedora (lo que es lo mismo que decir el autoempleo).

Sin embargo, al margen incluso de su posible ilegalidad, rechazo tajantemente la figura del ciudadano científico (Rodríguez Temiño, Matas 2013, 214, con referencias bibliográficas al respecto), la incorporación de la sociedad, de los habitantes de la ciudad o del territorio en los que se insertan el o los yacimientos estudiados, al proceso de investigación puro y duro, por muy integral, integradora o definitoria de un determinado modelo regional que se la considere ${ }^{15}$, o por mucho que los arqueólogos "tradicionales" o "al uso" seamos, supuestamente, especialistas "en confiscar materiales, fosilizar el pasado y convertir espacios vivos en ruinas arqueológicas" (Ayán, González, Rodríguez 2012, 79); de nuevo, una verdad sesgada, tendenciosa y sólo a medias. La horizontalidad en la investigación (Gago et alii 2013, 298 ss.), deseable en algunos aspectos, debe, por consiguiente, ser, cuando menos, matizada.

Todo tiene sus límites, y éste es, a mi juicio, uno de ellos, puesto que hay muchas vías para hacer partícipe de nuestro trabajo a la sociedad, sin necesidad de agregarla a las diversas etapas que conforman el mismo. ¿O es que se trata de limitarlo sólo a la parte instrumental...? Nadie sin la debida formación puede hacer profesionalmente interpretación histórica, supuesto el rigor metodológico y heurístico que exige. No creo que sea posible rebatir eso. Diferentes son las propuestas experimentales, para las que no se tiene por qué trabajar necesariamente con material arqueológico original, o poner en riesgo archivos del suelo de lectura única e irreversible. Prefiero, por consiguiente, la definición de Arqueología Pública como una "disciplina de autocrítica y de reconversión" (Almansa 2013b, 484), holística, transversal, inclusiva y de vocación integral, cuyo objetivo último es gestionar el conocimiento desde el más absoluto de los compromisos (epistemológico, pero también ético y deontológico), haciendo partícipe del mismo tanto a la comunidad científica como a la sociedad que nos sostiene y al entorno en el que desarrollamos nuestra labor.

$14 \mathrm{Y}$ es que parece haber acuerdo en que resulta necesaria "una recontextualización que permita conectar arqueología, sitios y poblaciones locales" (Ruiz Zapatero 2012, 61)

15 "Arqueología Pública a la gallega" (Ayán 2014, 94) 
Con todo, la incertidumbre, hoy, es tal que resulta imposible predecir el papel que dicha modalidad de Arqueología (entendida siempre en sentido laxo) desempeñará en el futuro de la disciplina en España. Por eso, estoy con E. Parga-Dans cuando afirma que nuestra ciencia ha de reinventarse, y que su futuro (al menos, en el campo de la arqueología comercial) pasa por numerosas oportunidades relacionadas con la formación, la polivalencia y la capacidad de adaptación (Berrocal 2014, 17); por supuesto, siempre desde el rigor, la excelencia, la autocrítica más severa, la formación sostenida, la innovación y un nuevo concepto de corporativismo.

\section{Porque no todo es excavar...}

Mi labor como profesional se ha desarrollado íntegramente en Andalucía. Han sido treinta y cinco años de carrera en paralelo con una Junta de Andalucía que al menos en materia de patrimonio arqueológico y por lo que se refiere en particular a Córdoba y provincia ha destacado por su discrecionalidad, su silencio muchas veces complaciente y sus concesiones no siempre comprensibles.

Es una realidad que conozco de primera mano por haberla vivido, lo que justifica que centre en ella mi discurso ${ }^{16}$. Este panorama, sin embargo, no es exclusivo de la Comunidad Autónoma Andaluza ${ }^{17}$ : en toda España la cantidad ingente de excavaciones practicadas durante los años del boom inmobiliario, además de simple "comparsa en el proceso especulador generado en su entorno", sólo ha servido para generar "ingentes cantidades de expedientes administrativos y colecciones de materiales que nadie estudiará jamás" (González Álvarez 2013, 166).

Se trata, pues, de un error mayúsculo, reiterado y de consecuencias irreversibles, del que es responsable directo el colectivo de arqueólogos, debido a la impericia, la falta de método, la avaricia y la connivencia de muchos presuntos profesionales (Hidalgo 2010, 7); subsidiario la Administración autonómica de Cultura, a la

16 Evidentemente, no soy el primero en acercarme con ojos más o menos críticos a la etapa autonómica de la Arqueología andaluza. Lo han hecho ya, entre otros, Salvatierra 1994, a-c; Rodríguez Temiño 2004, 2009, a y b, y 2010; Guarriarán, Salado 2009; Hidalgo 2010; Ventura 2010, para el caso específico de Córdoba; Aranda Jiménez 2011; Sánchez Romero 2011; León Muñoz 2012.; León Muñoz, Vaquerizo 2013, o Vaquerizo 1994, 2014 y 2015a. No pretendo, por tanto, ser original ni descubrir nada que no haya sido ya señalado; sólo dar mi versión de los hechos, desde la experiencia.

17 "La atomización de las responsabilidades en la gestión de los registros arqueológicos y la flagrante dejación en sus funciones y responsabilidades de las administraciones competentes, pueden ser la manifestación de los límites de un marco legal que no ha conseguido la aceptación del patrimonio como un bien común" (Gutiérrez Lloret 2011, 115). 
que corresponden las competencias absolutas en la materia ${ }^{18}$; y, por supuesto, co-responsables todos, por nuestro laissez faire más o menos militante.

Desde mediados de los años ochenta comienza una frenética actividad arqueológica de urgencia en las ciudades históricas andaluzas ${ }^{19}$ que, como es lógico, a pesar de su más que cuestionable ortodoxia ${ }^{20}$ ha originado infinidad de novedades. Sin embargo, salvo en el caso de que las Universidades hayan tomado cartas en el asunto, se mantienen básicamente inéditas, o han visto la luz de forma muy dispersa y limitada, en tal cantidad de publicaciones -de calidad muy desigual, por otra parte- que su recopilación y criba constituye hoy un objetivo casi inalcanzable.

La gravedad del desastre deriva de varios factores muy negativos para la arqueología urbana andaluza que sintetizo con extrema brevedad a continuación:

- Número desmedido y no siempre justificado de intervenciones de urgencia, favorecidas por el desarrollismo salvaje, la falta de planificación, un marco normativo avanzado y sin precedentes pero excesivamente laxo, y una permisividad cuestionable y con frecuencia silente por parte de las Administraciones públicas ${ }^{21}$.

- Criterios discrecionales en la concesión y planteamiento de las intervenciones, y de rigor, no suficientemente fiscalizado, en la obtención del registro. Intervenciones limitadas a las cotas de replanteo de las obras, conforme al principio de que el promotor sólo debe pagar por lo que destruye, desatendiendo en consecuencia la fase de investigación (Rodríguez Temiño 2010, 20 ss.) $)^{22}$.

18 "Una burocrática 'gestión de la destrucción patrimonial" que no deja de ser una prostitución del objetivo prístino del legislador" (Gutiérrez Lloret 2011, 115).

19 Los picos, como en el resto de España, se alcanzan entre 2000 y 2006, básicamente ligados a la actividad constructiva (Parga, Martín, Criado 2013, 177 s., Fig. 1).

20 Esta etapa se revela hoy como uno de los mayores atentados jamás vividos por los archivos del suelo andaluces; más dramático por cuanto ha tenido lugar con todas las bendiciones institucionales y en buena medida académicas.

21 "Algo que conviene con la nula preocupación por estas cuestiones de que hacen gala los responsables políticos y administrativos de alto nivel de las administraciones concernidas. Actitud secundada por muchos técnicos y profesionales" (Rodríguez Temiño 2010, 21 ss.)

22 Esta es una dinámica perversa que ha alejado a la Arqueología Urbana de cualquier criterio científico en la búsqueda más o menos planificada de información histórica, y que muy posiblemente, además, tiene los días contados, tras la devastadora crisis que estamos viviendo, las primeras sentencias por parte de algunos tribunales, y las nuevas e inquietantes iniciativas legisladoras de algunas Comunidades Autónomas, con base en el artículo 33 de la Constitución, relativo al derecho de propiedad (Díaz del Pozo, Torija, Zarco 2014). Es difícil imaginar qué será de la Arqueología Urbana cuando todo esto pase; sobre todo, porque no parece haber el menor interés por parte de ninguno de los agentes implicados en corregir errores pasados. 
- Utilización recurrente durante años, y con frecuencia indiscriminada, de medios mecánicos (Ventura 2010, 46) que han facilitado la destrucción de los niveles arqueológicos más recientes, y en muchas ocasiones también de los más antiguos.

- Vaciado sistemático de solares vitales para la resolución de problemas topográficos y urbanísticos de primer orden en relación con las diversas etapas históricas de nuestras ciudades ${ }^{23}$, generalmente amparados en la figura de Seguimientos arqueológicos que suponen con frecuencia la oficialización de las destrucciones ${ }^{24}$.

- Inexistencia de criterios de conjunto, de sostenibilidad y de futuro a la hora de integrar los escasos restos conservados en solares dispersos por toda la ciudad, desestructurados, descoordinados, inconexos, carentes de señalización global y unificada, descontextualizados y por tanto ininteligibles e inútiles para la comprensión global (también, la rentabilización cultural, educativa y turística) del gran yacimiento urbano $^{25}$.

- Ausencia casi absoluta de publicaciones, limitadas en buena medida al Anuario Arqueológico de Andalucía (Hidalgo 2010, 13 ss.), que recoge sin demasiado criterio los informes arqueológicos oficiales, en buena parte de los casos absolutamente inútiles ante la falta de lecturas estratigráficas y las carencias interpretativas, que no siempre dejan entrever la verdadera entidad de lo destruido. Esta dinámica,

23 “... la destrucción del yacimiento tras la excavación, es obviamente la opción que menos interfiere con el proceso de construcción de la ciudad y también tradicionalmente la más usual en Córdoba. La familiaridad con los restos arqueológicos, que parecen en la ciudad un recurso inagotable y socialmente poco valorado; la inercia de épocas pasadas; el creciente uso que la ciudad hace del subsuelo para aparcamientos; las exigencias del Plan General; los intereses del sector inmobiliario... Son otros tantos factores que explican esta situación" (Ventura 2010, 52-53). Estas atinadas palabras las escribe un Técnico de la Administración de Cultura en Córdoba que conoce bien la realidad de la que habla por haber participado directamente en ella; quizás por ello señala como razón determinante a la hora de decretar las destrucciones "que resultaría muy difícil sostener una línea de actuación de permanente conflicto con un sector tan importante como el inmobiliario". ¿Difícil, o políticamente poco rentable...?

24 Este mal, generalizable a toda España, fue denunciado por algunos autores antes incluso de que llegara la crisis: "La sensación general es que se está destruyendo mucho patrimonio, tanto en las ciudades como en los ámbitos rurales por una excesiva permisividad o por una aplicación muy interpretativa de las disposiciones legales y normativa vigente en la materia por aquellos que deberían velar por su aplicación. Por el contrario los movimientos ciudadanos son cada vez más activos y vigilantes..." (Martín-Bueno, Luesma 2006, 20).

25 "De esta forma, del conjunto descoordinado de acciones resulta una ciudad fragmentada y difusa que está lejos de presentarse como un conjunto formado por unidades de significado completo ... esqueleto de un programa educativo común...; parcelas conservadas de poca entidad y potencial turístico que sufren el riesgo de su fallecimiento por olvido, no sólo por parte de la sociedad sino por la propia administración" (Monzo 2010, 108 y 111). 
nada inocente ${ }^{26}$, puede extrapolarse de nuevo, en sus más diversos aspectos, a buena parte de España, aquejada en igual medida por el boom inmobiliario. Sirva como ejemplo Galicia (Ayán, González, Rodríguez 2012, 69).

- Dificultades administrativas de todo tipo a la hora de consultar los expedientes de excavación ${ }^{27}$; una realidad que contrasta dramáticamente con el hecho de que el trabajo científico sobre los datos recuperados en las últimas décadas se perfila como una de las escasas vías de futuro para la Arqueología española.

En definitiva, se ha dispuesto de los medios, pero, casi en una sublimación del método de ensayo y error, se ha equivocado en buena medida la gestión, provocando como efectos colaterales pérdidas de información y una destrucción del patrimonio arqueológico andaluz (caso, por ejemplo, de Cercadilla; Hidalgo 2010, 16 ss.) que sólo la investigación futura, desde una correcta perspectiva histórica, podrá evaluar en su plena dimensión. Y es que la continua interferencia de los intereses políticos en la gestión de la arqueología andaluza, así como la manipulación interesada de la opinión pública sumada al escaso celo profesional del colectivo, han tenido un efecto muy pernicioso sobre ella (Sada 2012, 153 ss.). Esto no es óbice para que Andalucía haya resultado pionera desde el primer momento sobre marco conceptual y legislación patrimonial (vid. estado de la cuestión reciente en Sánchez Romero, Rodríguez, Hernández 2012). El problema ha sido la materialización práctica de ambos; trasladarlos -y aplicarlos- a la dura realidad.

\section{El ejemplo de Córdoba}

Por su dilatada historia y sus características como yacimiento urbano, de extensión, potencia y complejidad inusuales, Córdoba ciudad representa un ejemplo arquetípico de todos los males que han aquejado a la arqueología andaluza desde que tuvo lugar la transferencia de competencias en materia de patrimonio desde el Gobierno central a la Junta de Andalucía y, casi enseguida,

26 "En un país de albañiles y camareros la eficacia del sistema no incluye hacer algo socialmente relevante con la arqueología. Ni a las excavaciones arqueológicas urbanas se les exigen memorias que expongan el resultado de la actividad acometida ni mucho menos se pide que tales memorias sean publicadas, puesto que su función primordial no es producir conocimiento, sino liberar solares de la "carga arqueológica" (Rodríguez Temiño 2009a, 15). El subrayado es mío.

27 Lo lógico sería que tales expedientes estuvieran disponibles para los investigadores en Internet, previa autorización. Se evitaría así chocar con el principio, básico e inalienable, de propiedad intelectual de los mismos (una discusión reciente al respecto en Rodríguez Temiño 2009b, 109 ss.). 
el inicio del pelotazo: enfrentamientos sostenidos entre las Administraciones responsables del patrimonio, de diferente signo político; indefinición en cuanto a los requisitos exigibles para ejercer la profesión de Arqueólogo; ausencia de un proyecto sistemático; caos metodológico; escasa cualificación de los profesionales; rigor insuficiente en los proyectos y las memorias de intervención; laxitud en los controles oficiales; discrecionalidad en las decisiones, etc.

En este contexto un poco apocalíptico no se salva nadie: no lo hacen las Administraciones públicas, incapaces o temerosas de aplicar de forma rigurosa la legislación vigente; tampoco la propia Universidad, cómplice en ocasiones de un dejar hacer que se encuentra en la base de grandes desastres arqueológicos ${ }^{28} ;$ y por supuesto menos que nadie los propios profesionales libres, atrapados en una dinámica vertiginosa en la que el trabajo de campo le ganó desde el primer minuto y por goleada la partida a la investigación, prácticamente nula, a pesar de los informes publicados en el Anuario Arqueológico de Andalucía, donde se recoge, sin rubor, criterio, o fondo científico alguno, más de una barbaridad difícilmente justificable. Así las cosas, y conforme a la inveterada costumbre hispana de mirar hacia otro lado, ha sido (es) fácil por parte de los colectivos implicados echar balones fuera acusando a los otros de desidia, incompetencia o mala gestión, mientras el yacimiento cordobés se desangraba (se desangra) a diario.

A día de hoy, en la mayor parte de nuestras ciudades históricas, de los restos excavados durante las tres últimas décadas sólo quedan ruinas dispersas, integradas con mayor o menor tino en bajos de edificios, aparcamientos o jardines, pero carentes por completo de un discurso histórico-patrimonial organizado. Dicho problema alcanza especial magnitud, y una gravedad realmente difícil de dimensionar por escrito, en el caso de Córdoba. A pesar del Plan General de Ordenación Urbana de 2001, en cuyo marco se inserta la Carta Arqueológica Municipal y una nueva normativa local consensuada con Cultura de la Junta de Andalucía que cambió por completo la forma de intervención en la ciudad (Murillo, Ventura, Hidalgo 1998-1999, y 1999; León Muñoz 2008 y 2012; León Muñoz, Vaquerizo 2012), la carencia de un plan estratégico, consensuado y a largo plazo, que habría permitido multiplicar recursos ${ }^{29}$, es la causa de que ese tejido arqueológico soterrado de la

28 Sin salir de Córdoba capital, a mi memoria vienen algunos hitos que destacan por la forma en que fueron gestionados y la pérdida patrimonial irreparable que propiciaron (Hidalgo 2010, 16 ss.). Las obras en el bulevar de Gran Capitán, la construcción de la estación de Alta Velocidad sobre el conjunto monumental de Cercadilla, el arrasamiento sistemático de algunos arrabales islámicos ( vid. infra), o los restos destruidos hace sólo un par de años al final de la Avda. de las Ollerías (entre otros muchos), son sólo parte de una realidad próxima en el tiempo que desde el punto de vista científico resulta cuando menos inquietante, y que no compete sólo a los arqueólogos, sino también a las Administraciones, en particular la autonómica, y por supuesto a quienes de una u otra forma lo hemos permitido.

29 Se ha pretendido "hacer de la necesidad virtud...; evocar el todo desde el fragmento..., musealizar la ciudad mostrando su profundidad básica" (Ventura 2010, 77-78), a todas luces de manera infructuosa, insostenible y errada. 
ciudad antigua ${ }^{30}$ pase completamente desapercibido a ciudadanos, visitantes y gestores del patrimonio, con la consiguiente pérdida de potencial, en sentido amplio. Dada, en consecuencia, su falta de retorno social, su nulo aporte a la herencia colectiva o las señas de identidad como grupo, tales actuaciones no pueden sino ser calificadas de una forma un tanto falaz de acallar conciencias, incluso de despilfarro; con mayor contundencia en el caso de aquéllas que se siguen abordando sin el más mínimo pudor hoy, cuando nuestro nivel de conocimiento sobre las relaciones entre ciudad histórica y patrimonio se ha incrementado exponencialmente respecto a los años del desarrollismo y a nada que uno arañe la superficie queda en evidencia el alcance sin precedentes del problema.

Reconozco las dificultades que ofrecerían en Córdoba proyectos de recuperación emblemáticos como el del teatro romano de Málaga (Corrales 2010), por sólo poner un ejemplo, pero sí que cabría exigir de cara al futuro un plan a largo plazo de rentabilización de recursos en el que prime a la hora de canalizar las inversiones el criterio histórico sobre el monumental (o, en el mejor de los casos, un equilibrio simbiótico entre ambos), conforme al principio minimalista de menos es más. Mientras tanto, sólo un programa riguroso, consensuado y holístico de valorización, integración y musealización de los pocos vestigios que han quedado, acompañado de la preceptiva investigación y de medidas normativas mucho más restrictivas en cuanto a la afección del subsuelo urbano, contribuirían en alguna medida a paliar la catástrofe, acercándonos así a ciudades más o menos modélicas al respecto como Barcelona (Beltrán de Heredia 2010), Tarragona (Macías 2010), Zaragoza (Aguarod, Erice, Mostalac 2005), Alcalá de Henares (Rascón, Sánchez 2005) y, muy especialmente, Mérida (Alba 2009 y 2012) ${ }^{31}$.

Es preciso conservar con criterio, señalizar de manera rigurosa, uniforme, global e innovadora, potenciar sin reservas el uso de las nuevas tecnologías, facilitar el acceso físico o virtual a los restos, crear rutas temáticas y cronológicas que permitan ofrecer a la ciudadanía un discurso diacrónico, coherente y completo sobre el gran yacimiento cordubense, una herramienta educativa y turística de primer orden que, sin duda, enriquecería de forma importante su oferta patrimonial. De lo contrario, tales integraciones acabarán provocando el efecto contrario, lanzarán a la sociedad, como de hecho ya hacen, un mensaje de abandono, peso muerto y falta de utilidad que dará de nuevo la razón a los detractores de la arqueología. Tras años de excavaciones desaforadas, es tiempo de estudio, imprescindible para incrementar nuestro conocimiento sobre la ciudad antigua y su evolución en el tiempo, pero también de aprovechar culturalmente lo

30 No siempre in situ y en su mayor parte inaccesible (Ventura 2010, 55 ss.), en un ejemplo paradigmático de lo que P. Monzo $(2010,137)$ ha llamado efecto sótano, y que ella misma califica con cierta ironía de broma consentida.

31 Vid. también, al efecto, la revista trimestral FORO, que publica el Consorcio de la Ciudad Monumental de Mérida. 
poco que hemos dejado. Por más que desde fuera sea difícil percibirlo, Córdoba es mucho más que el templo romano o la Mezquita...

\section{El Convenio GMU-UCO}

Así estaban las cosas cuando Universidad y Ayuntamiento de Córdoba decidieron aunar esfuerzos para intentar al menos poner un poco de orden en el caos (Murillo 2010; León Muñoz 2008; León Muñoz, Vaquerizo 2012; Ruiz Osuna, Ortiz 2012). Primero, fue la elaboración conjunta con técnicos del Ayuntamiento y la Delegación de Cultura de la Junta de Andalucía en Córdoba de una normativa municipal en el marco del Plan General de Ordenación Urbana y del Plan General para la Protección del Casco Histórico de Córdoba (Murillo, Ventura, Hidalgo 1998-1999 y 1999) que tomó forma en la Carta Arqueológica de Riesgo. Hablo de un documento de gestión que aglutinó la experiencia adquirida en el transcurso de aquellos primeros años, los cambios que en la normativa y modelos de gestión arqueológica suponía la aplicación del nuevo planeamiento urbanístico, y la dinámica cotidiana (en ella se sustentan de hecho, a día de hoy, las decisiones sobre la arqueología de la ciudad, tras vincular los diversos procedimientos administrativos), entendiendo por primera vez en el discurso arqueológico local la ciudad histórica como "yacimiento único".

Se materializaron de esta manera las recomendaciones al respecto de la Ley del Patrimonio Histórico Andaluz (art. 4.2) en relación con el papel activo que en materia de intervención, protección, conservación y difusión del patrimonio arqueológico deben desempeñar los municipios, incluida la zonificación arqueológica urbana. Y un factor determinante en esta nueva forma de abordar la arqueología cordobesa capitalina fue la implicación directa y activa de la Universidad, como coordinadora de estudios científicos de calidad sostenidos por un equipo multidisciplinar que desde el primer momento incorporó como prioridad absoluta unificar los sistemas de registro, al tiempo que sentaba las bases normativas para una mejora sustancial de la tutela y la gestión integral del patrimonio arqueológico, subyacente y emergente.

Más tarde, en 2001, se procedió a la firma de un convenio de colaboración entre el Área de Arqueología de la Universidad de Córdoba (UCO) y la Gerencia Municipal de Urbanismo (GMU), por el que establecimos un acuerdo conjunto sin antecedentes en la ciudad, que pretendía conectar la investigación universitaria con la realidad urbanística, económica, sociocultural y laboral de nuestro entorno más inmediato a fin de atender las múltiples necesidades del yacimiento urbano y su territorio; hacer una arqueología distinta en la que gestión e investigación fueran de la mano, en beneficio de la formación de arqueólogos integrales. Todo 
un reto, sin duda, que dio en pocos años un vuelco determinante a la forma de trabajar en la ciudad, al conocimiento de su secuencia histórica, pero que vio su fin de manera dramática, por iniciativa unilateral del nuevo Ayuntamiento de la ciudad, el 31 de diciembre de 2011 12 .

Con financiación de la GMU, que también ponía las instalaciones, un equipo de Investigadores de la UCO se encargó durante diez años (2001-2011), bajo la dirección de J.F. Murillo y de quien esto suscribe, de la ejecución técnica de las intervenciones arqueológicas promovidas por el Ayuntamiento, cualquier otra Administración Pública que así lo solicitaba, o los particulares acogidos al Programa de Fomento y Ayuda. Además del trabajo de campo en sí mismo (que exigió muchas renuncias, pero también acumuló logros), ambas instituciones pusimos especial énfasis desde el principio en varios objetivos que consideramos definidores de nuestra labor: la gestión, encaminada hacia un modelo de arqueología urbana que unificaba criterios y trataba de evitar errores pasados; la investigación en profundidad, con un método único y extrapolable que primaba el rigor en la documentación y la publicación de resultados; la formación de investigadores y la inserción laboral de nuestros egresados; la transferencia de los resultados obtenidos al entorno más inmediato, con una fuerte imbricación en su problemática educativa, cultural y socioeconómica, y, muy particularmente, la potenciación de la Arqueología como recurso de futuro y garantía de retorno económico ${ }^{33}$.

Fueron años de lucha interior para un buen número de jóvenes investigadores, pendientes de no caer en la tentación del dinero y los informes acomodaticios, de no perder el rumbo y mantenerse fieles a la idea de arqueología como ciencia

32 El convenio fue denunciado en septiembre de 2011, de manera unilateral y sin previo aviso, por el responsable de la Gerencia Municipal de Urbanismo del Ayuntamiento cordobés con el único argumento de que suponía un dispendio excesivo para las arcas públicas. No dijo, en cambio, cuánto se habían ahorrado (porque esta forma de trabajar, eludiendo el mercado libre, les permitió dividir el gasto por dos); que dicho dinero se había destinado exclusivamente a dar trabajo a entre treinta y cuarenta personas por año; que el equipo sostenido por el Convenio cambió por completo la gestión de la arqueología en Córdoba, trayendo algo de concierto al desconcierto; que la investigación sobre el yacimiento gravitó durante décadas y casi en exclusiva sobre nuestros hombros, o que éramos los únicos en hacer transferencia del conocimiento. Tampoco aludió a que con el cierre de esta iniciativa se ponía fin a una época, se daba muerte oficial a la Arqueología cordobesa sin plantear a cambio alternativa alguna.

33 “... producir la conversión del conocimiento arqueológico en patrimonio, que es el último eslabón del trabajo arqueológico: hacer socialmente visible lo invisible" (Ruiz Rodríguez 2011, 221). Efectivamente, hay que transmitir la información a la sociedad en términos que ella entienda, a cada uno según su nivel. Sólo si el ciudadano comienza a percibir la arqueología como recurso consigue disfrutar de ella como un elemento de recreación cultural y un factor de empleo y de reactivación económica; esas "piedras" que tan presentes están en nuestra cotidianeidad dejarán de ser el problema que hoy son, para convertirse justo en lo contrario. Basta pensar en ciudades como Tarragona o Mérida, donde han triunfado iniciativas de tanta trascendencia como el Proyecto Mecenas, para saber de lo que hablo. 
histórica comprometida con la interpretación y la difusión últimas del yacimiento que tratábamos de transmitirles, frente a otras opciones y posibilidades mucho más rentables. Una labor callada y comprometida, muy criticada en su momento por sus propios colegas "comerciales", incapaces de entender que alguien antepusiera la ética al enriquecimiento fácil, y atacada con saña después de que cayera el mercado inmobiliario, cuando muchos de aquéllos quedaron en la calle, mientras la mayor parte de quienes se preocuparon de formarse y atenerse a criterios de rigor siguieron en activo todavía un tiempo, hasta que el estado del bienestar acabó por explotar definitivamente. Y es que la crisis de la "burbuja inmobiliaria" ha sido dramática en Córdoba. Tras casi dos décadas de vacas gordas, durante las cuales la antigua capital de la Bética y del Califato Omeya de Occidente generó trabajo para una legión de empresas y arqueólogos libres (del más variado tenor y no siempre movidas por intereses científicos), la caída del mercado inmobiliario dejó en la calle y sin trabajo a la mayor parte de ellos, algunos de los cuales nutren todavía un colectivo resentido y desubicado, poco dado a continuar su formación y capaz de las mayores ignominias con tal de bombardear el mismo sistema del que hasta hace muy poco han formado parte activa.

Esto no quiere decir que nuestra actuación fuera perfecta. Hicimos mucho, sí, pero aún quedó más por hacer. Nuestro trabajo debe ser considerado, por tanto, como perfectible y, en cualquier caso, limitado. Córdoba es mucho yacimiento como para darlo por concluido. Quedan multitud de aspectos por tratar, infinidad de problemas por resolver, incógnitas del más variado tipo por investigar. Con nuestras publicaciones nos limitamos en último término a añadir un eslabón más a la cadena, desde el compromiso, la firmeza, la profesionalidad, la modestia, y si se quiere también la cautela ${ }^{34}$. La Arqueología es cualquier cosa menos una ciencia estática. Todo es provisional, nada inmutable, y bien conscientes de ello tratamos de no dogmatizar, abordando una visión diacrónica de la ciudad desde la prudencia y la convicción de que sólo se hace camino andándolo, por cuanto es posible que en pocos años muchas de nuestras hipótesis queden superadas. Pero la ciencia histórica funciona así, a base de confirmar, matizar o corregir formulaciones que en su momento se tuvieron por acertadas. Eso es lo que intentamos hacer a diario en el ejercicio de nuestra actividad (aun cuando sea cada vez más difícil), transmitiéndolo del mismo modo a quienes confían en nuestras enseñanzas.

Hablo de un desafío que no ha hecho sino empezar. Somos la primera generación que se dedica en Córdoba a la Arqueología como profesión en sentido estricto, a pesar de la no existencia oficial de ésta. Detrás vendrán quienes, sin duda, nos enmendarán la plana, quizá incluso de forma inmisericorde, implacable

34 Además de la producción individual de cada uno de sus miembros, nuestro Grupo de Investigación sostiene tres series periódicas de divulgación científica: Anales de Arqueología Cordobesa, Anejos de Anales de Arqueología Cordobesa, y Monografías de Arqueología Cordobesa. 
y descarnada como por desgracia es habitual entre el colectivo. Mientras tanto, nos damos por satisfechos con haber sentado las bases de un modelo de gestión, investigación y difusión (que no rentabilización) del patrimonio arqueológico de Córdoba entendida como yacimiento único sin referencias previas siquiera comparables. ¿Que nos hemos quedado a medio trayecto...? Probablemente. ¿Qué de alguna manera hemos sido partícipes de la hecatombe? Pues es posible. En la guerra nadie consigue sustraerse del todo, salir indemne. Pero al menos lo intentamos, clamamos aún hoy a diario por que los responsables de turno acaben de comprender la potencialidad de la Arqueología antes de que acaben por desaparecer definitivamente sus archivos del suelo ${ }^{35}$.

\section{Arqueología somos todos: una responsabilidad que se pretende compartida}

A principios de 2011, y como derivación lógica de los diez años de investigación arqueológica casi frenética realizada en el marco del Convenio entre el Grupo de Investigación que dirijo y la Gerencia Municipal de Urbanismo del Ayuntamiento de Córdoba (vid. supra), un nutrido grupo de profesionales pusimos al servicio de Córdoba un proyecto inédito de transferencia y gestión del conocimiento basado en el derecho básico e inalienable de la sociedad a la información, que poco a poco se ha ido consolidando y hoy llama la atención dentro y fuera de nuestras fronteras (Cardona 2015, 94). Hablo del ya citado Arqueología somos todos (www.arqueocordoba.com) (Vaquerizo, Ruiz 2013 y 2015; Ruiz, Vaquerizo 2014; Vaquerizo 2014, 2015, a-c y 2016, a-b), que, de modo absolutamente voluntarista por parte de quienes lo integramos, y sin perder nunca nuestro carácter fundamental de arqueólogos e historiadores, está desarrollando las herramientas, los protocolos y las actuaciones necesarios para acercar los resultados de la investigación arqueológica al ciudadano de a pie, ofreciendo la información en tantos niveles y formatos como creemos pertinentes desde el punto de vista didáctico (Cardona 2015, 87 ss.) para facilitar en último extremo su comprensión, su asunción y su integración como factor sostenible de educación, de cultura y también de dinamización. Se trata de un proyecto vivo, abierto y en permanente construcción que pretende integrar, nunca excluir, aunar sinergias y concitar apoyos.

35 "La nueva realidad requiere de una administración que permita transferir a la sociedad de forma adecuada los valores culturales de nuestro patrimonio-creando puentes- por los que fluya la información, la crítica, la colaboración, los problemas, las dificultades o los aciertos, rompiendo la barrera del aislamiento, cuando no de incomprensión, que actualmente existe entre los diferentes agentes de la arqueología andaluza" (Aranda Jiménez 2011, 17). Es, en esencia y con otras palabras, lo mismo que yo defendía un poco más arriba. 

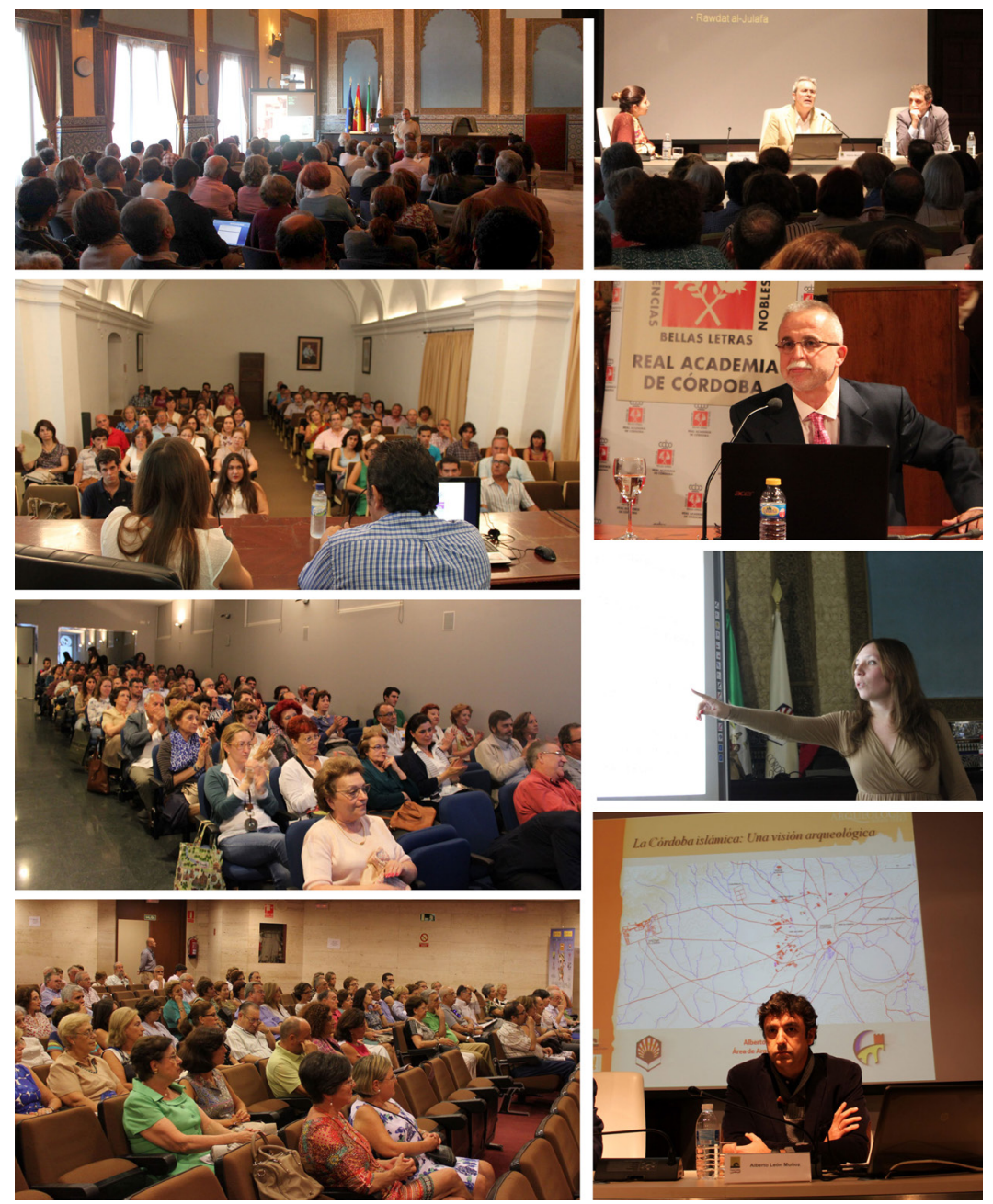

Fig. 1. mágenes de algunas de las conferencias que se vienen impartiendo en muy diversas sedes y a cargo de un variadísimo elenco de profesionales desde 2011 en el marco de AST.

Arqueología somos todos, en cuyas rutas ${ }^{36}$, exposiciones, conferencias, talleres, viajes y actividades de todo tipo (Láms. 1-3) han participado ya muchos miles de cordobeses, se acerca así, aun cuando sólo tangencialmente, a los parámetros

36 Uno de nuestros objetivos es explicar la ciudad en perspectiva diacrónica facilitando el acceso a la ciudadanía a restos de diferentes épocas conservados en el subsuelo (garajes, cocheras, sótanos...) que permiten trabar discursos cronológico-temáticos muy diversos sobre la Córdoba antigua. Es una iniciativa similar a las Rutas del Patrimonio Desconocido que gestiona en Toledo el Centro de Gestión de Recursos Culturales del Consorcio de la Ciudad (htttp://www.consorciotoledo.com), y que en nuestro caso viene tomando forma en un nuevo concepto de Guía Didáctica, de las que ya han visto la luz una decena de entregas. 
de "una arqueología pública que debe ir más allá de la transparencia informativa y la divulgación para materializar procesos de empoderamiento propios de una arqueología en comunidad", como los que rigen proyectos de filosofía semejante, pero quizá no tan moderados en algunos de sus planteamientos, como el ya mencionado de A Lanzada (Sanxenxo, Pontevedra) (Ayán, González, Rodríguez 2012, 63).

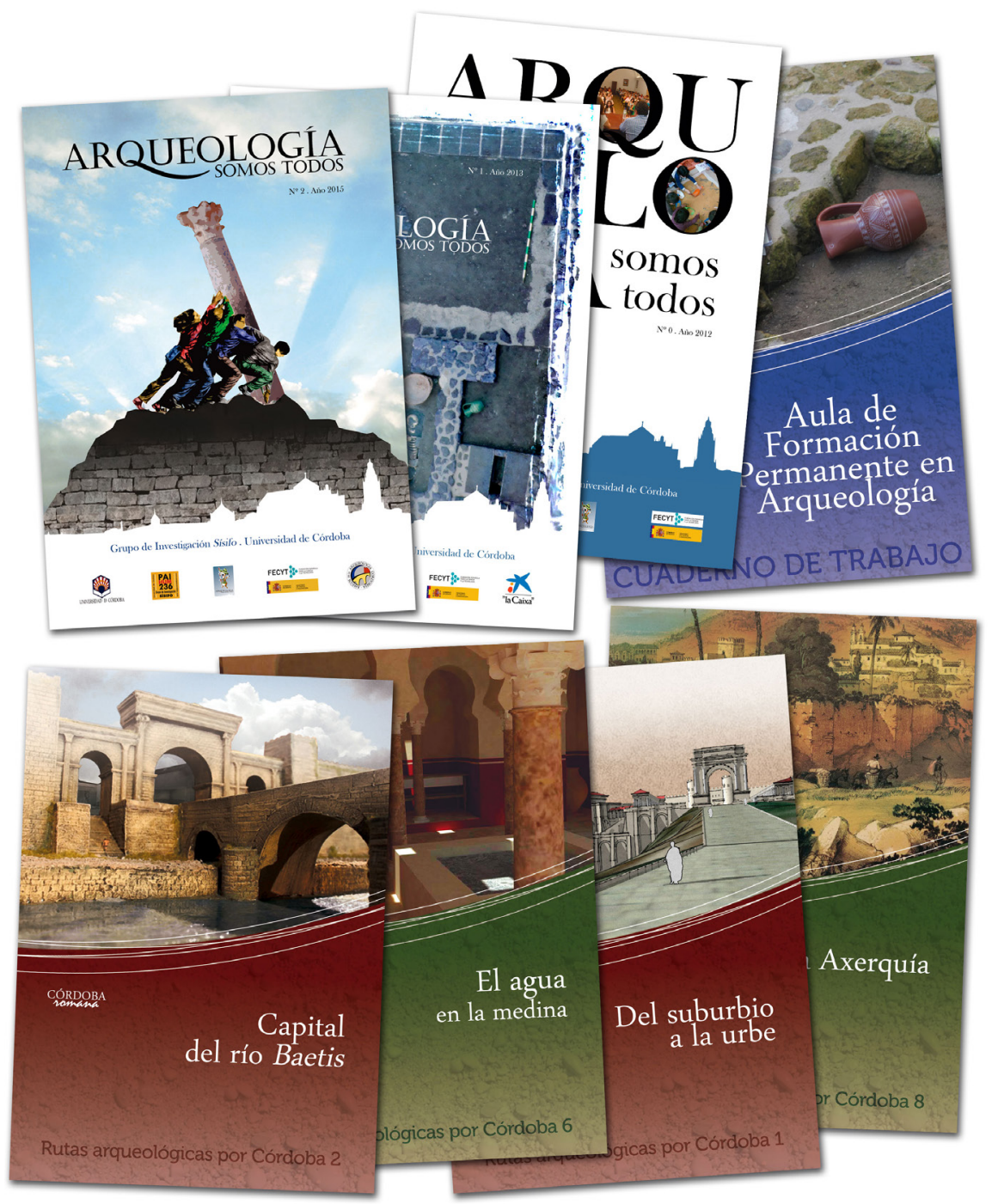

Fig. 2. AST es un proyecto universitario que pretende en último término transferir a la sociedad los resultados de nuestra propia investigación. En esta labor son fundamentales nuestras publicaciones, entre las cuales un Boletín semestral y un nuevo concepto de Guías Didácticas en cuya edición están colaborando otras instituciones. 
Apoyamos nuestras propuestas en las más modernas metodologías, que pretenden aportar una nueva forma de acercamiento al hecho arqueológico desde la objetividad, la riqueza de matices y el rigor, básicos para evitar cualquier tipo de banalización, reñida sin duda con el objetivo último de divulgación histórica que perseguimos. Se trata de un modelo de difusión arqueológica adaptado a la capital cordobesa pero extrapolable a cualquier otra ciudad histórica o unidad territorial, que, coherente con los principios fundamentales que han regido hasta ahora nuestra trayectoria (ya expresados más arriba), busca el equilibrio entre la labor básica de investigación, la gestión integral, la salvaguardia del yacimiento y la transferencia a la sociedad del conocimiento histórico generado, de cara a su transmutación última en motor de empleo y factor sostenible de reactivación social, cultural y económica.
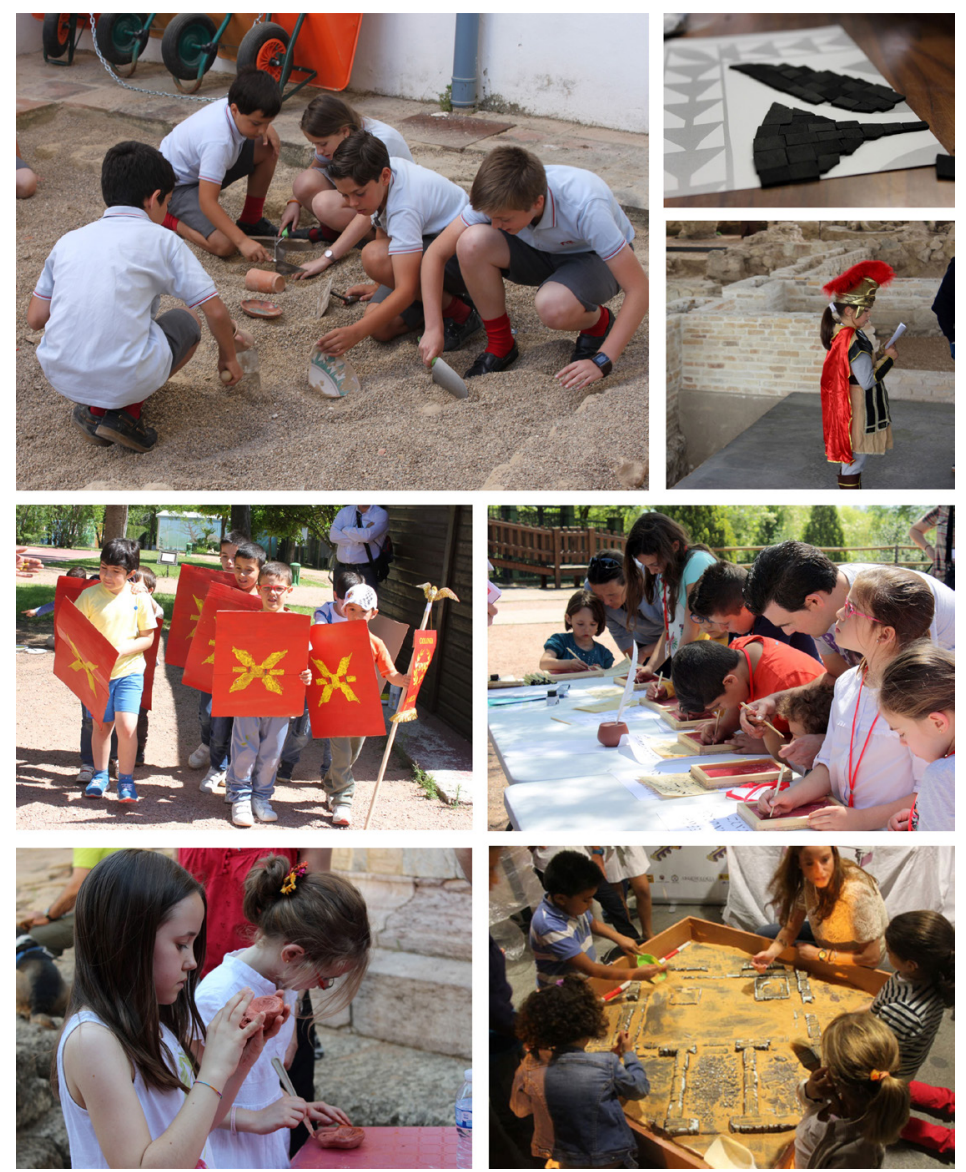

Fig. 3. AST nació con el objetivo fundamental de difundir, pero también de educar. Por eso, nuestros talleres van encaminados a los más diversos niveles de enseñanza, incluida Primaria, entre cuyos alumnos tienen un éxito enorme. 
Tenemos como finalidad añadida concienciar a la ciudadanía -y, con ella, a responsables políticos y Administraciones públicas- de que la arqueología constituye el manantial más importante y regular de novedades sobre el pasado de Córdoba, y el estudio y la gestión de lo excavado fuente de empleo de potencialidad indiscutible, intentando de paso acabar con la visión peyorativa tradicional de dicha ciencia; todo un reto, si tenemos en cuenta la escasa receptividad al respecto de unos y otros (Vaquerizo 2015b, 3). Con la crisis ha Ilegado la hora de reinventarse, de emprender nuevas apuestas, de corregir nuestra forma de acercarnos a la disciplina y de revertir sus resultados a la sociedad que nos sostiene, en un ejercicio consciente de lo que se ha dado en llamar socialización del patrimonio que, en pocas palabras, pretende ser el germen de una cultura compartida (Cardona 2015, 90); educar a la ciudadanía (Lám. 4) con el fin de generar conciencia colectiva y que sea ella misma la que, implicándose, reclame con criterio el consumo y la intervención programada, sistemática y estratégica sobre aquél; repartir de modo consciente las responsabilidades a la hora de gestionarlo, disfrutarlo y también rentabilizarlo (que no investigarlo), siempre desde un punto de vista integral, y tanto por lo que se refiere al patrimonio subyacente como al emergente.

Este fue el espíritu que guió desde su puesta en marcha AST, en cuyas propuestas vienen participando generosamente no sólo arqueólogos, sino también arquitectos, médicos, ingenieros, físicos, gestores patrimoniales, asociaciones, etc., en un ejemplo claro de acercamiento multidisciplinar que demuestra por sí mismo la transversalidad de la arqueología, su capilarización como ciencia histórica, pero también social, capaz de devolvernos el orgullo de pertenecer a una tierra y a un grupo: los nuestros.

Córdoba lleva demasiado tiempo apostando por una idea de promoción de su cultura que prima el espectáculo sobre manifestaciones más profundas de la misma, como la historia o el patrimonio; y sin educación no hay conocimiento, ni criterio, ni tampoco respeto por un legado monumental que merece ser difundido sin duda, pero después de -he ahí la clave- ser investigado, protegido, señalizado, expuesto $^{37}$. Nosotros, en cambio, creemos que otra forma de entender la cultura es posible, que nuestros jóvenes pueden vivir de profesiones relacionadas con el estudio, la investigación y la difusión en sentido amplio del pasado, y, modestamente, AST es buena muestra de ello ${ }^{38}$. Se suma así nuestro esfuerzo al de otras Administraciones autonómicas o locales, empresas, particulares o colectivos diversos, que a día de hoy, sin embargo, actuamos descoordinados. Habría, pues,

37 La disciplina arqueológica admite muchas vías, muchos niveles de difusión, desde el más estrictamente científico, reservado sólo a unos pocos, al puramente divulgativo, de consumo mayoritario. Sin embargo, una cosa es cultura y otra muy diferente banalización.

38 En el momento de entregar estas líneas contamos con una decena de investigadores contratados, varios becarios en formación, un nutrido grupo de voluntarios culturales y varios alumnos de Grado y Postgrado en prácticas. Es decir, en momentos de crisis y regulaciones de empleo, nosotros lo estamos generando. ¿Cabe mayor triunfo...? 
que sumar capacidades y esfuerzos, diseñar el modelo de ciudad que queremos legar a nuestros hijos, dar forma a un organismo capaz de poner orden en este maremágnum, racionalizar ideas, rentabilizar recursos, y a partir de ahí potenciar vías de difusión y explotación que, sin perder nunca de vista las claves básicas de nuestra historia, se conviertan en salida laboral para muchos de nuestros jóvenes, en una forma efectiva de cambiar su destino.
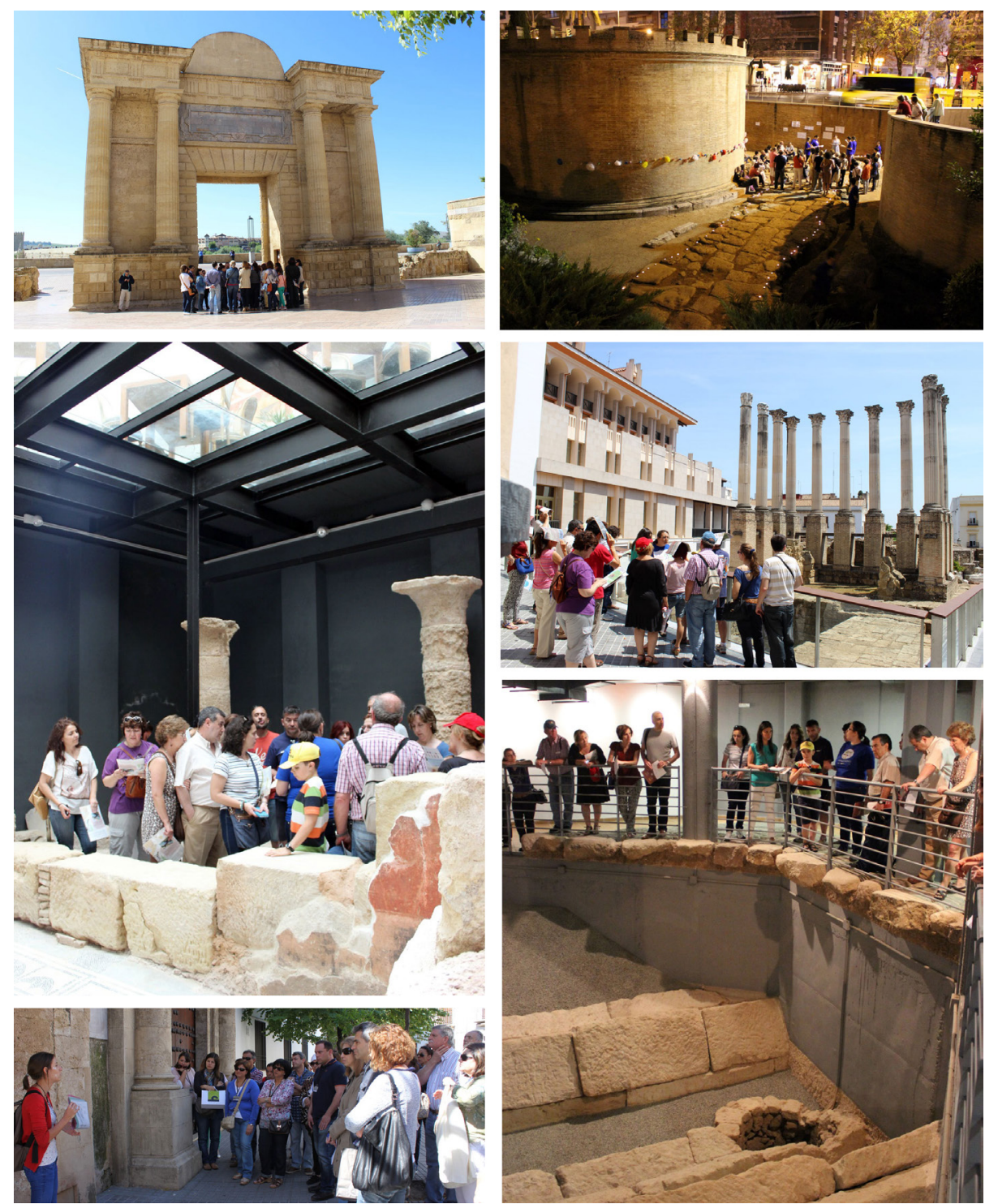

Fig. 4. Rutas temáticas desarrolladas en el marco de AST. Incluyen tanto patrimonio arqueológico emergente como otros muchos restos conservados en sótanos y garajes, habitualmente no accesibles a la ciudadanía. 

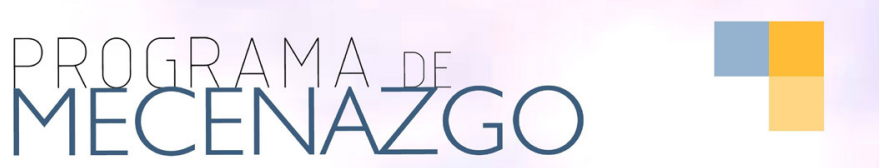

\section{ARQUEOLOGÍA}

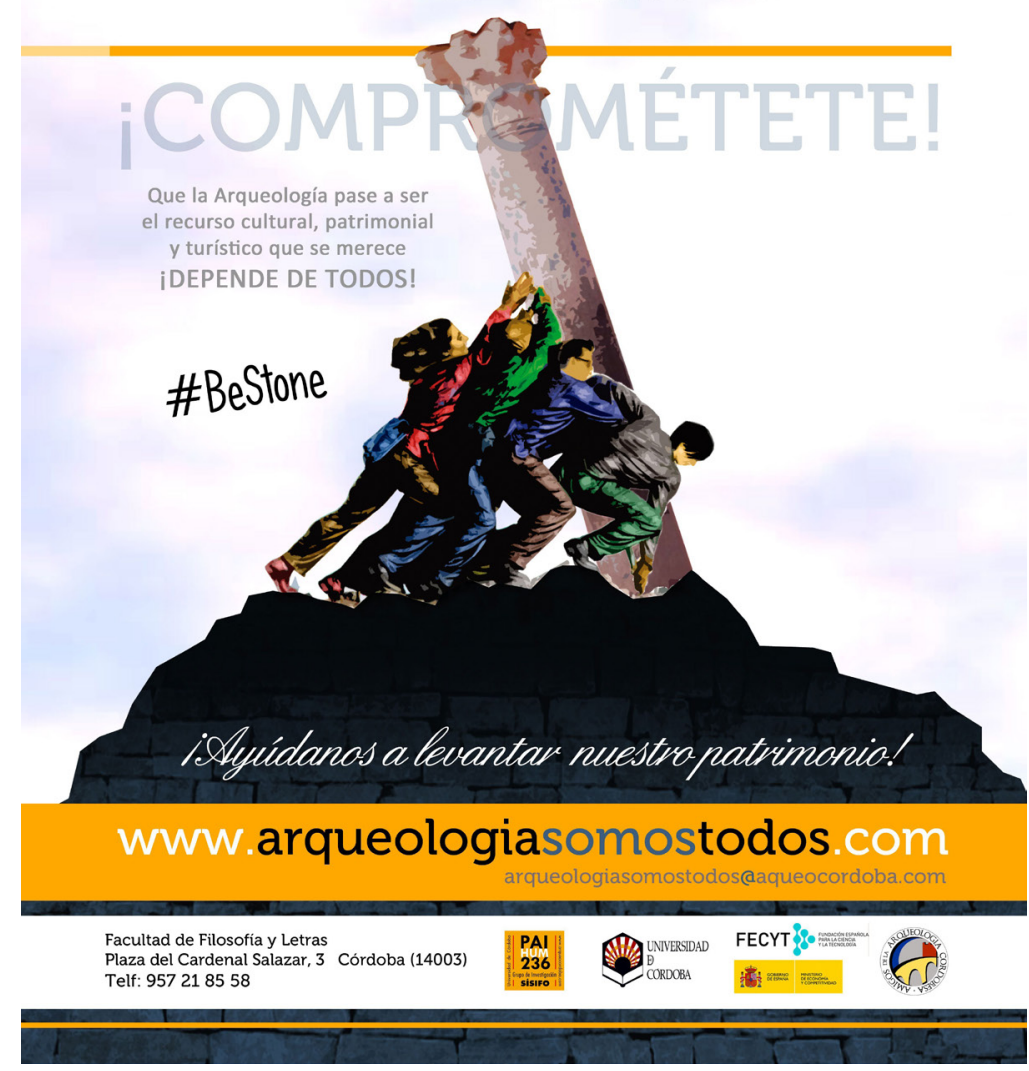

Fig. 5. La última iniciativa emprendida en el marco de $A S T$ pretende implicar a la ciudadanía en la investigación, protección, difusión y rentabilización del patrimonio arqueológico mediante un proyecto de mecenazgo activo y sostenido en el tiempo.

Como contrapartida y estímulo a nuestro empeño (un tanto quijotesco, por qué no reconocerlo ${ }^{39}$ ), la sociedad parece estar valorando muy positivamente la labor que realizamos, si hemos de juzgar por el seguimiento de nuestras actividades, el reflejo en prensa, o los numerosos reconocimientos recibidos desde el momento

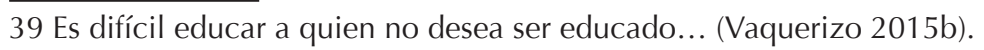


mismo en que pusimos en marcha el proyecto (Lám. 5) ${ }^{40}$. Y es que, por fortuna, a pesar de mil y una zancadillas, de tener que sortear a diario multitud de piedras en el camino, de darnos de frente una y otra vez con molinos de viento, no estamos solos. En el último año nuestra página web ha recibido casi dos millones de visitas, y son muchos miles los ciudadanos que nos siguen a diario; también a través de las redes sociales.

Del mismo modo, contamos con el apoyo institucional o económico de diversos colectivos, empresas y organismos, entre los cuales no quiero dejar de citar aquí de nuevo, por el papel relevante que han desempeñado en la buena marcha y consolidación de AST, el Ministerio de Economía y Competitividad, la Fundación Española para la Ciencia y la Tecnología, integrada en el mismo ${ }^{41}$, el Ministerio de Educación, Cultura y Deporte, la Fundación Obra Social "la Caixa", el Ayuntamiento de Córdoba, Casa Árabe, la Fundación Descubre, el Parque de las Ciencias de Granada, etc.

Desde $A S T^{42}$ entendimos enseguida que la sociedad era nuestro destinatario último, que debíamos hacer el proyecto participativo y abierto (vivo...). Por esa razón constituimos a principios de 2013 la Asociación Cultural homónima, sin ánimo de lucro, que además de permitir la colaboración de personas físicas y jurídicas se ha convertido en una vía de apoyo y sostenimiento al Grupo de Investigación; y no hace mucho acabamos de poner en marcha los Amigos de la Arqueología Cordobesa, plataforma activa de mecenazgo ciudadano que, fiel al concepto de socialización que antes invocaba, permite a la sociedad civil comprometerse y apoyar -en la medida de sus posibilidades y con distintos grados de implicación- la investigación, la protección y la difusión del patrimonio arqueológico de Córdoba y su provincia (http://www.arqueologiasomostodos.com/ amigos/amigos.html), al tiempo que disfrutar de ellas (Lám. 6). Nuestro modelo encuentra su referente más cercano en el Proyecto Mecenas del Consorcio de la Ciudad Monumental de Mérida, que acoge también la adopción de monumentos

40 Locales: Premio Juan Bernier de Arqueología, otorgado por la Asociación Arte Arqueología e Historia de Córdoba (2011); Premio a la Recuperación del Patrimonio Histórico-Artístico de Córdoba, convocado por la Fundación Caja Rural en 2011; Premio Averroes de Oro Ciudad de Córdoba a las Ciencias (2011); Premio Córdoba Joven del Instituto Andaluz de la Juventud (2012); Premio Transferencia del Conocimiento a la Sociedad del Consejo Social de la Universidad de Córdoba) (2013). Nacionales: Fundación Obra social "La Caixa" (2013) y Premios Vaccea del Centro de Estudios Vacceos 'Federico Wattenberg' (2014). Internacionales: Mención especial de los Premios Europa Nostra en su categoría de Educación, Formación y Sensibilización (2014).

41 La Fecyt ha sido la principal valedora de Arqueología somos todos desde sus inicios. Además de concedernos hasta la fecha varios proyectos de diverso alcance, en 2012 nos consiguió, en el marco de su convenio "para apoyar algunos de los proyectos más destacados de cultura científica que se desarrollan en nuestro país", el respaldo económico suplementario de la Obra Social "La Caixa", y más recientemente (2014) nos ha incluido en su // Catálogo de Prácticas Inspiradoras en Cultura Científica.

42 Un análisis mucho más detenido de la filosofía del proyecto y de las actividades realizadas hasta la fecha puede consultarse por ejemplo en Vaquerizo, Ruiz 2013 y 2015; Ruiz, Vaquerizo 2014. 
por parte de los centros educativos emeritenses, en una adaptación del programa internacional "La scuola adotta" que ha conseguido cautivar a centros educativos de toda Europa, con una fuerte repercusión también en Cataluña ${ }^{43}$.

Además de otros dos de mucho alcance con el Ministerio de Cultura y la Fecyt, respectivamente, en esos momentos desarrollamos además el proyecto de $\mathrm{I}+\mathrm{D}+\mathrm{i}$ "Del registro estratigráfico a la sociedad del conocimiento: el patrimonio arqueológico urbano y rural como agente de desarrollo sostenible", concedido a nuestro Grupo de Investigación por el Ministerio de Economía y Competitividad en el marco del Programa estatal de Investigación, Desarrollo e Innovación orientada a los retos de la sociedad (Convocatoria 2013, Modalidad 1: Proyectos de I+D+I; Ref.: HAR2013-43389-R), con la colaboración de investigadores de Italia, Alemania, Portugal, Mérida y Córdoba.

Pretendemos con él generar un espacio único de colaboración multidisciplinar, intersectorial e internacional que, a través de la investigación científica, la transferencia del conocimiento y sus respectivas aplicaciones prácticas, trate de resolver problemas y carencias actuales de la sociedad, al tiempo que abra nuevas vías de desarrollo para la disciplina (entre otras, servir de base para nuevos proyectos de impacto internacional cada vez más acusado y de alcance); un modelo extrapolable, como decía, a cualquier otra ciudad histórica o a muy diversos ámbitos territoriales, que se sustenta en un principio rector de potencialidad futura indiscutible: la divulgación de excelencia como factor capaz de retroalimentar la investigación.

Un congreso internacional, varias reuniones científicas, la edición de un Manual de Buenas Prácticas, la creación de una plataforma web con contenidos abiertos en línea, el diseño de material didáctico para docentes y discentes, información arqueológica al servicio de ciudadanos, investigadores y tour-operadores, etc., nos convertirán en una fuente de información primordial, en un generador de propuestas de actuación de las que, posteriormente, podrán beneficiarse administraciones y empresas privadas. Así lo han hecho ya de algunos de nuestros programas e iniciativas pasadas, como demuestran la proliferación en la ciudad de rutas arqueológicas por parte de jóvenes emprendedores, los ciclos de conferencias sobre temas históricos a cargo de muy diversas instituciones, los recorridos en bicicleta por el casco histórico como valor de accesibilidad, la presencia de talleres didácticos y divulgativos en multitud de centros educativos y en varios arqueódromos diseminados por Córdoba y provincia, la asunción como propias de nuestras nuevas sugerencias didácticas y tecnológicas, o la incorporación del "somos todos" para las más variadas propuestas patrimoniales, reivindicativas o de mecenazgo ${ }^{44}$.

43 Vid., por ejemplo, en este sentido, algunos de los trabajos incluidos en Treballs d'Arqueología 15 (2009), que publica la Universidad Autónoma de Barcelona.

44 Sirva como ejemplo la campaña de crowfunding montada por el Ayuntamiento de Écija para la restauración del mosaico de El Picadero destrozado por los expoliadores: https://www.facebook. com/video.php? $v=1610490425832444 \&$ fref $=$ nf 


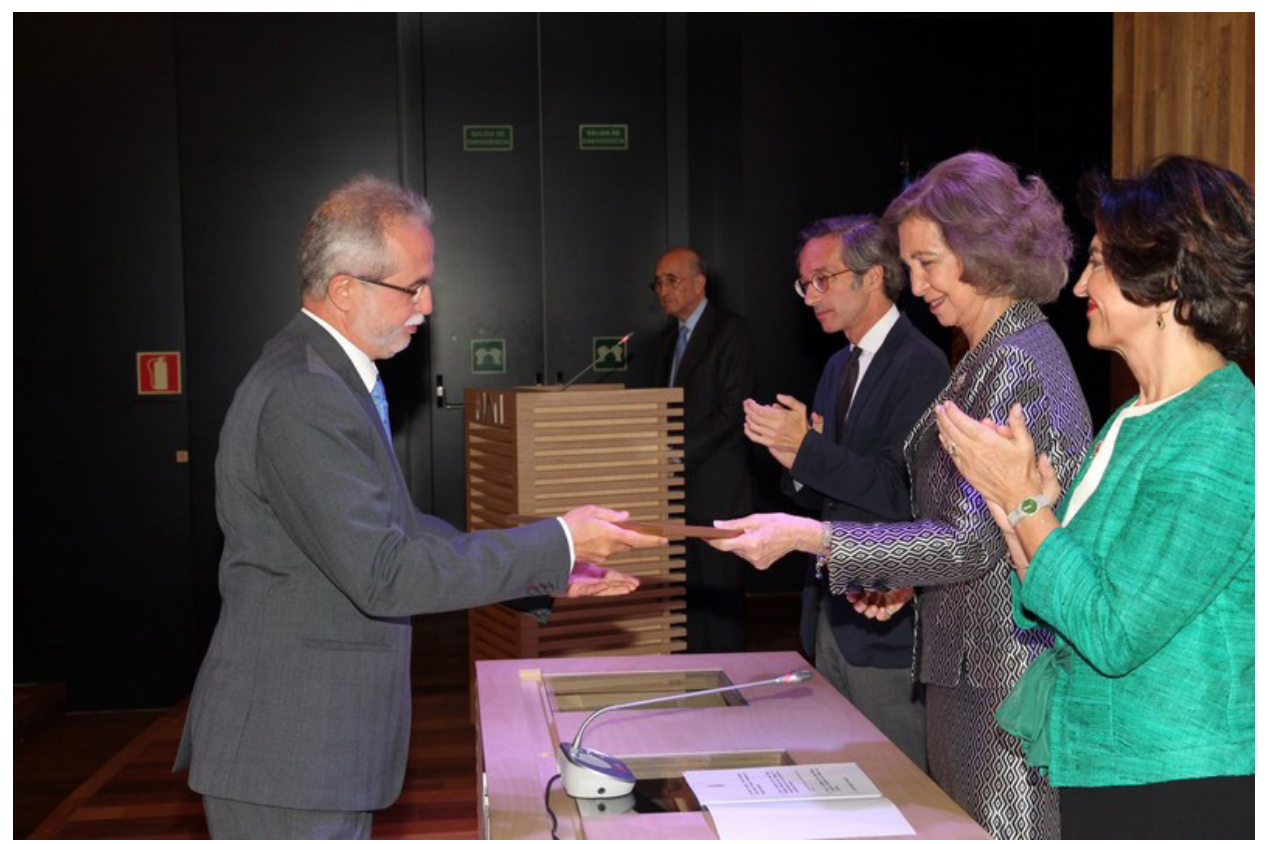

Fig. 6. Entrega por parte de la Reina Dña. Sofía de la distinción especial conseguida por AST en el marco de los Premios Europa Nostra 2014 al director del Proyecto, el día 17 de abril de 2015 en el Museo Arqueológico Nacional de Madrid.

Son, pues, los poderes públicos y agentes responsables quienes no terminan de entender, ni de asumir, las vías de desarrollo casi infinitas que ofrece nuestro patrimonio arqueológico, cuya gestión necesita con urgencia de un organismo autónomo de carácter transversal, sostenido por capital público y privado, que garantice con afán estratégico y responsable la investigación de calidad, la formación científica sostenida y la inserción laboral de profesionales en el ámbito de la Arqueología urbana y del territorio, preste apoyo a la ciudadanía desde el más estricto de los compromisos en lugar de enfrentarse a ella, evite los espectáculos superfluos y las duplicidades, rentabilice recursos, y permita una intervención programada al margen de los ciclos políticos ${ }^{45}$. Y, para ser justos, hemos de reconocer que la desunión, las desavenencias y las diferencias de criterio en el seno de nuestro colectivo, no ayudan precisamente a ello.

Se trata, en último extremo, de propiciar la elaboración de un Plan Director (o Proyecto de Ciudad) que, con independencia de planificar al detalle la gestión del yacimiento, con base en la Carta Arqueológica de Riesgo y la colaboración de todas las Administraciones, se comprometa de forma activa, integral e inclusiva con la investigación, la protección, la conservación, la difusión y la puesta en valor del patrimonio arqueológico cordobés; evite problemas para el desarrollo urbanístico

45 En mi cabeza está de nuevo, cuando escribo estas palabras, el Consorcio de la Ciudad Monumental, Histórico-Artísitca y Arqueológica de Mérida. 
y facilite las cosas a promotores públicos o privados; transforme la investigación fundamental en aplicada, el conocimiento en riqueza, la formación en criterio; acerque la labor universitaria al conjunto de la sociedad y, por último, refuerce el papel de la Arqueología como ciencia histórica, agente de desarrollo, yacimiento de empleo y elemento dinamizador, potenciando de paso la cultura emprendedora y el mecenazgo.

"Hay que fijarse en lo que se ha hecho bien y en quienes lo han hecho bien para tomar ejemplo. No tendremos disculpa si no hacemos todos lo poco y lo mucho que está en nuestras manos, en las de cada uno, para que no se pierda lo que tanto ha costado construir, para asegurar a nuestros hijos un porvenir habitable, si no los alentamos y los adiestramos para que lo defiendan. Ya no nos queda más remedio que empeñarnos en ver las cosas tal como son, a la sobria luz de lo real. Después de tantas alucinaciones, quizás sólo ahora hemos llegado o deberíamos haber llegado a la edad de la razón..."46. Termino, como empecé, con una cita de nuestro ilustre y sagaz Premio Príncipe de Asturias de las Letras A. Muñoz Molina perfectamente extrapolable al mundo de la Arqueología. Hemos vivido un sueño; de pronto, todo lo que parecía superfluo se ha convertido en imprescindible; recibimos cada mañana un baño inmisericorde de realidad que nos ha colocado frente al peor de los espejos; tratamos, no sin esfuerzo, de aceptar con humildad nuestro papel real en el mundo. Es llegada, pues, la hora de reflexionar sin cortinas de humo, asumir con gallardía los errores y construir el futuro con lo mejor que tenemos; y entre esos recursos la arqueología representa sin duda un activo de primera importancia, particularmente en el caso de las ciudades históricas. No asumir su enorme potencialidad actuando en consecuencia (por parte de todos) es un pecado de temeridad que, como estamos sufriendo ya, acaba siempre pasando factura.

\section{Bibliografía}

AGUAROD, C.; ERICE, R.; MOSTALAC, A. (2005), "Caesaraugusta, cuatro temas para un solo contexto urbano", III Congreso Internacional sobre musealización de yacimientos arqueológicos. De la excavación al público. Procesos de decisión y creación de nuevos recursos, Alcalá de Henares, pp. 137-144.

ALBA, M. (2009), "La problemática en la gestión de las ciudades Patrimonio Mundial: el caso del Conjunto Arqueológico de Mérida", El patrimonio

46 A. Muñoz Molina, Todo lo que era sólido, Ed. Seix Barral Biblioteca Breve, $10^{\mathrm{a}}$ ed., Barcelona 2014, pp. 252-253. 
Mundial en España: una visión crítica. Patrimonio Cultural de España, $n^{\circ} 2$, Madrid, pp. 232-249.

- (2012), "El Consorcio de la Ciudad Monumental Histórico-Artística y Arqueológica de Mérida. Una institución al servicio del Patrimonio". Catálogo de la exposición: El Consorcio y la arqueología emeritense. De la excavación al Museo, Mérida, pp. 15-25.

ALBELDA, V.; PARDO, S.; REAL, C. (2013), "Espiera. Ejemplo de activismo social desde una asociación", en Almansa, J. (Ed.), Arqueología Pública en España, Madrid, pp. 317-332.

ALMANSA, J. (Ed.) (2011a), El futuro de la Arqueología en España, JAS Arqueología Editorial, Madrid

- (2011b), "Analizando el futuro de la arqueología española", en ALMANSA, J. (Ed.), El futuro de la Arqueología en España, JAS Arqueologia Editorial, Madrid, pp. 263-287.

- (2011c), "Arqueología para todos los públicos. Hacia una definición de la Arqueología Pública 'a la española', ArqueoWeb 13, 87-107.

— (Ed.) (2013a), Arqueología Pública en España, Madrid.

- (2013b), "Epílogo", en Almansa, J. (Ed.), Arqueología Pública en España, Madrid, pp. 475-485.

ANDREU, J.; GARCÍA, J.F. (2013), "El Plan de Investigación de Los Bañales (Uncastillo, Zaragoza). Cuando el patrimonio arqueológico sirve a la formación y al desarrollo local", en Almansa, J. (Ed.), Arqueología Pública en España, Madrid, pp. 273-290.

ARANDA JIMÉNEZ, G. (2011), "Presente y futuro de la Arqueología en Andalucía", en ALMANSA, J. (Ed.), El futuro de la Arqueología en España, San Fernando de Henares (Madrid), pp. 13-19.

AYÁN, X. (2014), "Arqueología Pública en las Comunidades Autónomas de Galicia", La Linde 3, Valencia, pp. 93-138.

AYÁN, X.; GAGO, M. (2012), Herdeiros pola forza. Patrimonio cultural, poder e sociedade Nela Galicia do século XXI, 2.0 Editora, Ames.

AYÁN, X.M.; GONZÁLEZ, M.; RODRÍGUEZ, R.M. (2012), "Más allá de la arqueología pública: arqueología, democracia y comunidad en el yacimiento multivocal de A Lanzada (Sanxenxo, Pontevedra)", Treballs d'Arqueologia 18, Barcelona, pp. 63-98.

BELTRÁN DE HEREDIA, J. (2010); “Pasado y presente en las ciudades vivas. El patrimonio arqueológico en la ciudad de Barcelona: distintas opciones para su puesta en valor", en Hidalgo, R. (Coord.), La ciudad dentro de la ciudad. La gestión y conservación del patrimonio arqueológico en ámbito urbano, Sevilla, pp. 231-256. 
BERROCAL, P. (2014), “La arqueología profesional en España analizada desde la Sociología. Entrevista a Eva Parga-Dans, Socióloga", La Linde 3, Valencia pp. 12-18 (edición electrónica).

BONACCHI, Ch. (2009), “Archeologia pubblica in Italia. Origini e prospettive di un 'nuovo' settore disciplinare", Ricerche Storiche 2-3, pp. 329 - 350.

BRUNER, E. (2012), "Hay vida en la torre de marfil: señales de humo desde un laboratorio de evolución humana", en Barros del Río, M.A. (Ed.), Comunicación social de la Ciencia. Estrategias y retos, Burgos, pp.26-38.

CARDONA, G. (2015), "Pero... ¿de verdad esto es importante? La didáctica de la Arqueología desde la Academia y la investigación", La Linde 4, Valencia, pp. 83-100.

DÍAZ DEL POZO, D.; TORIJA, A.; ZARCO, E. (2014), "Una nueva ley de patrimonio histórico para la CAM. Reflexiones en torno a un camino accidentado", Panorama. Revista PH Instituto Andaluz del Patrimonio Histórico n 85, abril, pp. 6-10.

GAGO, M. et alii (2013), "A Torre dos Mouros (Lira, Carnota). Una experiencia de ciencia en comunidad y comunicación en directo", en Almansa, J. (Ed.), Arqueología Pública en España, Madrid, pp. 291-316.

GONZÁLEZ ÁLVAREZ, D. (2013), "Del precariado a la nada. La situación laboral de la Arqueología Comercial en el Estado Español a comienzos del s. XXI", en Almansa, J. (Ed.), Arqueología Pública en España, Madrid, pp. 151-168.

GURRIARÁN, P., SALADO, J.B. (2009), "Arqueología urbana en el sur peninsular: problemática de una actividad incipiente", en Domínguez Arranz, A. (ed.): Patrimonio arqueológico a debate. Su valor cultural y económico, Huesca, pp. 51-61.

GUTIÉRREZ LLORET, S. (2011), "La arqueología ensimismada", en ALMANSA, J. (Ed.), El futuro de la Arqueología en España, San Fernando de Henares (Madrid), pp. 111-117.

HENSON, D. (2009), "Friend or enemy?: Community Archaeology in the United Kingdom", Treballs d'Arqueologia 15, Barcelona, pp. 43-49.

HIDALGO, R. (2010), "La ciudad dentro de la ciudad: reflexiones sobre la gestión y conservación del patrimonio arqueológico en ámbito urbano en Andalucía", en Hidalgo, R. (Coord.), La ciudad dentro de la ciudad. La gestión y conservación del patrimonio arqueológico en ámbito urbano, Sevilla, pp. 5-21. HOLTORF, C. (2007), Archaeology is a brand! The meaning of Archaeology in contemporary popular culture, Oxford.

LA LINDE (2013), "La Arqueología Pública. Un soplo de aire fresco. Entrevista a Antonio Vizcaíno Estevan", La Linde 1, Valencia, pp. 9-23.

LEÓN MUÑOZ, A. (2008), "Hacia un Nuevo modelo de gestión arqueológica en Córdoba. El Convenio GMU-UCO", AnAAC 1, Córdoba, pp. 11-15. 
- (2012), "Public administration of archaeology in Spain. Notes on the current situation and future prospects", Post-Classical Archaeologies 2, Mantova, pp. 337-360.

LEÓN MUÑOZ, A.; VAQUERIZO, D. (2012), "Un nuevo modelo de gestión de la Arqueología Urbana en Córdoba", en Beltrán, J.; Rodríguez, O. (Eds.), Hispaniae Urbes. Investigaciones arqueológicas en ciudades históricas, Sevilla, pp. 321-361.

LIVERANI, P. (2011), "Public Archaeology, riflessioni preliminari", in Vannini, G. (a cura di), Archeologia Pubblica in Toscana. Un progetto e una proposta, Firenze, pp. 113-118.

MARÍN SUÁREZ, C. et alii (2013), "El blog 'Arqueología de la Guerra Civil'. Un proyecto entre la ética y la estética", en Almansa, J. (Ed.), Arqueología Pública en España, Madrid, pp. 419-437.

MARTíN-BUENO, M.; LUESMA, R. (2006), "La Arqueología como factor de desarrollo en la sociedad actual", Mainake XXVIII, Málaga, pp. 11-26.

MARTÍNEZ VALLEJO, A. (2014), "La mendicidad en las exhumaciones de la Guerra Civil", La Linde 3, Valencia, pp. 157-167.

MERRIMAN, N. (Ed.) (2004), Public Archaeology, London.

MONZO, P. (2010), "Patrimonio arqueológico en la ciudad de Sevilla: cuidados y olvidados", en Hidalgo, R. (Coord.), La ciudad dentro de la ciudad. La gestión y conservación del patrimonio arqueológico en ámbito urbano, Sevilla, pp. 107-142.

MOYA-MALENO, P.R. (2013), "El 'Entorno Jamila' (Villanueva de los Infantes, Ciudad Real, España). De la iniciativa personal a un proyecto de gestión integral de la investigación arqueológica", en Almansa, J. (Ed.), Arqueología Pública en España, Madrid, pp. 351-374.

MURILLO, J. F. (2010): "La gestión del patrimonio arqueológico en Córdoba. Balance de una década" en AAVV, Arqueología. Patrimonio Histórico y urbanismo en las ciudades Patrimonio de la Humanidad de España, Tarragona, 87-127.

MURILLO, J. F.; VENTURA, Á.; HIDALGO, R. (1998/99), "El planeamiento urbanístico y la Gestión del Patrimonio Arqueológico en Córdoba", Kobie 25, 45-73.

- (1999), "Intervención arqueológica y planeamiento urbanístico en Córdoba", Recuperar la memòria urbana. L'arqueologia en la rehabilitació de les ciutats històriques (Tarragona, 1997), Tarragona, 75-99.

PARGA, E.; MARTÍN, C.; CRIADO, F. (2013), "Innovación organizativa y de gestión. La clave de la sostenibilidad de las empresas de arqueología", en Almansa, J. (Ed.), Arqueología pública en España, Madrid, pp. 169-186. 
PULIDO, A.J. (2008), "La Arqueología como instrumento de rentabilidad social y económica: el ejemplo de Córdoba", AnAAC 1, Córdoba, pp. 321-338.

RASCÓN, S.; SÁNCHEZ,A.L. (2005), “DeComplutumal Burgo de San Justo. Distintas opciones para la conservación y puesta en valor del patrimonio arqueológico de Alcalá de Henares", III Congreso Internacional sobre musealización de yacimientos arqueológicos. De la excavación al público. Procesos de decisión y creación de nuevos recursos, Alcalá de Henares, pp. 39-44.

RODRÍGUEZ SANTANA, C.G.; CORREA, T. (2013), “¡Hola! Me Ilamo Arminda... ¿y tú?. Un programa de comunicación en el Museo y Parque Arqueológico Cueva Pintada", en Almansa, J. (Ed.), Arqueología Pública en España, Madrid, pp. 249-272.

RODRÍGUEZ TEMIÑO, I. (2004), Arqueología urbana en España, Barcelona.

- (2009a), "Repensar la Arqueología Urbana", Anuari d'Arqueologia i Patrimonio de Barcelona 2009, Barcelona, pp. 15-24.

- (2009b), "Notas sobre la regulación de las actividades arqueológicas", Patrimonio Cultural y Derecho 13, Madrid, pp. 87-115.

- (2010), "Arqueología urbana en tiempos de crisis", en Arqueología, patrimonio histórico y urbanismo en las ciudades Patrimonio de lo Humanidad de España. Actas de las Jornadas Técnicas sobre Arqueología, Patrimonio Histórico y Urbanismo (Tarragona. 2009), Tarragona, pp. 17-29.

RODRÍGUEZ TEMIÑO, I.; MATAS, F.J. (2013), Arqueólogos contra 'piteros', 'piteros' contra arqueólogos. Superar una incomprensión", en Almansa, J. (Ed.), Arqueología pública en España, Madrid, pp. 187-217.

RUIZ OSUNA, A.; VAQUERIZO, D. (2014), "La Cultura Científica como factor de emprendimiento en el marco de la Ciudad Histórica. El modelo de Arqueología somos todos", Forum Ciudades y Territorios Creativos de España, Gran Canaria.

RUIZ OSUNA, A.; ORTIZ URBANO, R. (2012), "Un nuevo modelo de gestión arqueológica en Córdoba: el Convenio GMU-UCO", en Peinados Herreros, $\mathrm{M}^{\mathrm{a}} \mathrm{A}$. (Coord), I Congreso Internacional El patrimonio natural y cultural como motor de desarrollo: investigación e innovación, Sevilla, 590-609.

RUIZ RODRÍGUEZ, A. (2011), “De la heterotopía al lugar común del conocimiento", en Almansa, J. (Ed.), El futuro de la Arqueología en España, San Fernando de Henares (Madrid), pp. 217-222.

RUIZ ZAPATERO, G. (2012), "Presencia social de la Arqueología y percepción pública del pasado", en Aavv, Construcciones y usos del pasado. Patrimonio Arqueológico, territorio y museo, Valencia, pp. 31-73.

SADA, P. (2012), "Patrimonio arqueológico, aprendizaje de la historia y educación", en Aavv, Construcciones y usos del pasado. Patrimonio Arqueológico, Territorio y Museo, Valencia, pp. 153-176. 
SALVATIERRA, V. (1994a), "Historia y desarrollo del modelo andaluz de Arqueología", TP51.1, Madrid, pp. 1-13.

- (1994b), "El nuevo Reglamento de Actividades Arqueológicas de la Junta de Andalucía", Boletín del Instituto de Estudios Giennenses 152, abril-junio, pp. 227-238.

— (1994c), "Arqueología urbana: investigación y gestión. La situación en Andalucía", Arqueología y Territorio Medieval 1, Universidad de Jaén, pp. 75-82.

SÁNCHEZROMERO, M. (2011), "Planificando las políticas públicas sobre patrimonio arqueológico en Andalucía", en Almansa, J. (Ed.), El futuro de la Arqueología en España, San Fernando de Henares (Madrid), pp. 227-232.

SÁNCHEZ ROMERO, M.; RODRÍGUEZ, S.I.; HERNÁNDEZ, J. (2012), "Sociedad y patrimonio: políticas públicas", Treballs d'Arqueologia 18, Barcelona, pp. 9-29.

SIMPSON, F. (2009), "Evaluating the value of community archaeology: the XArch Project", Treballs d'Arqueologia 15, pp. 51-62.

SKEATES, R.; McDAVID, C.; CARMAN, J. (Eds.) (2012), The Oxford Handbook of Public Archaeology, Oxford University Press.

VANNINI, G. (2011), Archeologia pubblica in Toscana. Un progetto e una proposta, Firenze.

VAQUERIZO, D. (1994), "Arqueología de Gestión/Arqueología de Investigación: ¿Disyuntiva o complemento?". Cassandra 1994-2. Commentari, Appunti, Segnalazioni di Storia dell'Arte, Archeologia, Normativa Istituzionale, Demo-Etno-Antropologia. Raccolti dall'A.N.C.O. S.T. Roma, 9-21.

- (2014), En precario... Reflexiones desde el pasado, con vocación de futuro, Conferencias Inaugurales II (Curso 2014-2015), Máster en Estudios Avanzados e Investigación en Historia (Sociedades, Poderes, Identidades), Universidad de Salamanca.

- (2015a), "Arqueología para un futuro incierto... La profesión de Arqueólogo tras la crisis devastadora del Pelotazo", Pyrenae 46.2, Barcelona, pp. 89-120.

- (2015b), "Reinventare il futuro... Verso un modello integrale e sostenibile di ricerca, gestione e difussione del patrimonio archeologico a Cordova, paradigma di città storica", Archeologia e parchi archeologici. Sperienze a confronto, Aquileia, pp. 64-91.

- (2015c), "Arqueología para un futuro incierto... o crónicas del desencuentro", Pyrenae 46.2, Barcelona, pp. 139-146.

- (2016a), "L'Accademia come fattore determinante della socializzazione del patrimonio archeologico", en Bonetto, J. et alii (a cura di), I mille volti del passato. Scritti in onore di Francesca Ghedini, Roma, pp. 1029-1038. 
VAQUERIZO, D.; RUIZ, A. (2013), "Arqueología somos todos..., o la necesidad de (re)inventarse", en Almansa, J. (Ed.), Arqueologra pública en España, Madrid, pp. 221-247.

- (2015), “¿Socializar el patrimonio? 'Arqueología somos todos': un modelo de cultura científica en (por y para) Córdoba, ciudad histórica", Hispania Nostra. Revista para la defensa del Patrimonio Cultura y Natural 17, Madrid, pp. 4651.

VENTURA, J.T. (2010), "Presencias del patrimonio arqueológico en la ciudad de Córdoba. 1997-2007", en Hidalgo, R. (Coord.), La ciudad dentro de la ciudad. La gestión y conservación del patrimonio arqueológico en ámbito urbano, Sevilla, pp. 41-80.

VILA, A. etalii(2014), "Trovelschool, una iniciativa de arqueología autogestionada", La Linde 2, Valencia, pp. 156-161. 